\title{
Predicting early data revisions to US GDP and the effects of releases on equity markets
}

Article

Accepted Version

Clements, M. P. and Galvão, A. B. (2017) Predicting early data revisions to US GDP and the effects of releases on equity markets. Journal of Business \& Economic Statistics, 35 (3). pp. 389-406. ISSN 0735-0015 doi:

https://doi.org/10.1080/07350015.2015.1076726 Available at https://centaur.reading.ac.uk/42102/

It is advisable to refer to the publisher's version if you intend to cite from the work. See Guidance on citing.

To link to this article DOI: http://dx.doi.org/10.1080/07350015.2015.1076726

Publisher: Taylor \& Francis

All outputs in CentAUR are protected by Intellectual Property Rights law, including copyright law. Copyright and IPR is retained by the creators or other copyright holders. Terms and conditions for use of this material are defined in the End User Agreement.

www.reading.ac.uk/centaur 
Central Archive at the University of Reading

Reading's research outputs online 


\title{
Predicting Early Data Revisions to US GDP
}

\section{and the Effects of Releases on Equity Markets}

\author{
Michael P. Clements \\ ICMA Centre \\ Henley Business School \\ University of Reading \\ M.P.Clements@reading.ac.uk
}

Ana Beatriz Galvão*

Warwick Business School

University of Warwick

Ana.Galvao@wbs.ac.uk

July 20, 2015

\begin{abstract}
The effects of data uncertainty on real-time decision-making can be reduced by predicting data revisions to US GDP growth. We show that survey forecasts efficiently predict the revision implicit in the second estimate of GDP growth, but that forecasting models incorporating monthly economic indicators and daily equity returns provide superior forecasts of the data revision implied by the release of the third estimate. We use forecasting models to measure the impact of surprises in GDP announcements on equity markets, and to analyse the effects of anticipated future revisions on announcement-day returns. We show that the publication of better than expected third-release GDP figures provides a boost to equity markets, and if future upward revisions are expected, the effects are enhanced during recessions
\end{abstract}

Key words: survey forecasts, data revisions, economic indicators, stock returns, macro announcements.

JEL code C53.

\footnotetext{
*Michael Clements is also an Associate member of the Institute for New Economic Thinking at the Oxford Martin School, University of Oxford. Ana Galvão acknowledges support for this work from the Economic and Social Research Council [ES/K010611/1]. Corresponding author: Dr. Ana Beatriz Galvao; email: ana.galvao@wbs.ac.uk.
} 


\section{Predicting Early Data Revisions to US GDP and the Effects of Releases on Equity Markets}

The effects of data uncertainty on real-time decision-making can be reduced by predicting data revisions to US GDP growth. We show that survey forecasts efficiently predict the revision implicit in the second estimate of GDP growth, but that forecasting models incorporating monthly economic indicators and daily equity returns provide superior forecasts of the data revision implied by the release of the third estimate. We use forecasting models to measure the impact of surprises in GDP announcements on equity markets, and to analyse the effects of anticipated future revisions on announcement-day returns. We show that the publication of better than expected third-release GDP figures provides a boost to equity markets, and if future upward revisions are expected, the effects are enhanced during recessions.

Key words: survey forecasts, data revisions, economic indicators, stock returns, macro announcements.

JEL code C53. 


\section{Introduction}

Orphanides (2001) brought to the attention of economists the difference between taking policy decisions in real-time using the early estimates of real output and inflation that are then available compared to using the final-revised data only available a number of years later. Revisions to national accounts data are large enough to cause the policy rate implied by the real-time Taylor rule to differ significantly from the rate computed with revised data. Data uncertainty also affects financial market participants. The calendar of 'market-moving' indicators published on the Econoday website (www.econoday.com) includes not only the advance estimate of real GDP, published up to one month after the end of the observation quarter, but also the second and the third estimates, released, respectively, two and three months after the end of the observation quarter. Indeed the results of Gilbert, Scotti, Strasser and Vega (2015) on the impact of macroeconomic news on bond and currency markets establish that markets react to surprises (differences between the published values and the market expectation) in the second release of real GDP. Gilbert (2011) also provides evidence that equity markets react not only to surprises in the initial release, but also to expected future revisions, indicating that markets care about the revised values of economic activity measures.

In this paper we consider the extent to which the early monthly data revisions of GDP are predictable. Following current usage, we refer to the Bureau of Economic Analysis (BEA) three GDP estimates released at monthly intervals, following the reference quarter, as the advance, second and third estimates (see, e.g., Fixler, Greenaway-McGrevy and Grimm (2014)). (The second and third estimates were formerly known as the 'preliminary' and 'final' estimates). We begin with the survey forecasts of the second and third estimates, made subsequent to the advance and second estimates, respectively, having been released. Of interest is whether the survey forecasts are able to predict the data revisions contained in the second and third releases, and how the accuracy of these forecasts compares with that of forecasting models which make judicious use of monthly economic indicators and daily financial data available at the time the survey forecasts were made. If survey 
forecasters are not able to predict early data revisions, or if they underperform relative to the model, then the usual practice of proxying market expectations by survey expectations is suspect for the early GDP releases. For example, the event studies literature investigates the response of financial markets to new information provided by the release of measures of economic activity (see, e.g., McQueen and Roley (1993), Andersen, Bollerslev, Diebold and Vega (2003) and Faust, Rogers, Wang and Wright (2007)), and generally relies upon survey forecasts to calculate what constitutes new information.

Our findings suggest there are sources of information - not incorporated in survey expectations - which can be used to predict the third release of US GDP. We provide an assessment of the effects of surprises in the second and third releases of GDP on daily equity returns, allowing that market expectations may not be accurately measured by survey expectations. Equity markets are found to respond to unanticipated news about GDP estimates, and the magnitude of the response to the third release is increased when model forecasts are used to calculate surprises, consistent with the model forecasts better proxying market expectations. We also find that during recessions investors respond to the information the GDP release carries about future data revisions, consistent with Gilbert (2011). We extend the analysis to consider the effects of expected and surprise revisions between the new release and the true value. We find that, during recessions, upward revisions in the third release GDP figures boost equity markets arising both from expected and surprise revisions.

The predictability of revisions depends on the nature of the revisions to already published data. Uncertainty about the current state of the economy will decrease with the publication of revised estimates which incorporate new information, and which may also reduce the measurement noise component of the earlier estimates. Following Mankiw and Shapiro (1986), economists classify data revisions as news when they add new information, and noise when they reduce measurement error. If data revisions are noise, they can be predicted based on the current estimate. Mankiw and Shapiro (1986) and Faust, Rogers and Wright (2005) provide empirical evidence that data revisions to US real GDP are largely news, while Aruoba (2008) and Corradi, Fernandez and Swanson (2009) found some limited predictability of data revisions, in particular of initial revisions. Clements and 
Galvão (2012) exploit multiple-vintage models to show that real-time estimates of output and inflation gaps can be improved by using predictions of data revisions following the encouraging results of Garratt, Lee, Mise and Shields (2008). Predictable data revisions suggest that we are able to reduce current data uncertainty in real time.

Much of the literature has used the quarterly vintages recorded in the Real Time Data Set for Macroeconomists (RTDSM: see Croushore and Stark (2001)), where the first estimate is the advance estimate (as used here) but the estimate available in the following quarter corresponds to the third estimate. Consequently, the predictability of the monthly revisions to the advance estimate (i.e., of the second estimate relative to the third, and of the third relative to the second) has not been addressed. Note that given the earlier estimate is in the information set, then forecasting the new estimate, or the revision between the two estimates, is obviously equivalent, and we can refer to the predictability of revisions or estimates.

The nature of the process by which the national accounts data are revised suggests that the initial monthly revisions may be predictable even if the revisions are 'news' in the sense that they are unpredictable based on information at the time the first estimate (or an earlier estimate more generally) was made. As described by Landefeld, Seskin and Fraumeni (2008), 25\% of the GDP components at the time of the release of the first estimate are trend-based data obtained from extrapolations supported by related indicator series. The proportion of trend-based data in the second and third estimates is $23 \%$ and $13 \%$ respectively. As a consequence, it might be possible to exploit the economic indicator data published prior to the release of the GDP figure to predict that figure.

We evaluate different methods of forecasting the BEA's early releases of GDP data: survey data, forecasting models with economic indicators, and models with financial indicators. The quality of survey forecasts of new observations has been extensively evaluated (see, e.g., Ang, Bekaert and Wei (2007) for a recent appraisal), but we are not aware of any explicit assessments of survey forecasts of the revisions to initial releases, that is, of the second and third estimates. Evans (2005) compares model-based real-time measures of output growth with the MMS (International Money 
Market Services) survey median forecasts of the three initial releases of GDP growth. However, the comparison was made to evaluate the models, with the MMS forecasts taken as the target values.

The plan of the rest of the paper is as follows. In section 2 we describe the survey data, and the accuracy of the median forecasts of the second and third estimates of output growth. Section 3 evaluates the forecast accuracy of forecasting models exploiting information sets comprising monthly economic indicators and daily financial data. Section 4 analyses the impact of the mis-measurement of market expectations on estimates of the effects of data release announcements on equity returns. It also analyses whether announcement-day returns are affected by future expected revisions to the GDP figures induced by the announced value. Section 5 offers some concluding remarks.

\section{Using Surveys to Predict Revised Estimates}

When predicting the second and the third GDP releases in real time, we are able to use an earlier release. The advance estimate (published on average 30 days after the end of the quarter, and denoted $y_{t}^{t+1 / 3}$ ) can be used to predict the second release (published on average 60 days after the end of the observational quarter, denoted $y_{t}^{t+2 / 3}$ ), and the second estimate can be used to predict the third estimates (published on average 30 days later than the second estimate, and denoted $y_{t}^{t+1}$ ). Here and throughout we use the convention that the superscripts are the release dates (in months, as fractions of quarters), and the subscripts are the dates the observations refer to (in quarters). A no-change forecast suggests that the revision is not predictable. The no-change forecast of the second estimate is: $\hat{y}_{t}^{t+2 / 3}=y_{t}^{t+1 / 3}$, and the short-horizon no-change forecast of the third estimate

(made when $y_{t}^{t+2 / 3}$ is known) is simply $\hat{y}_{t}^{t+1}=y_{t}^{t+2 / 3}$. The accuracy of no-change forecasts serve as a benchmark for the forecasting models in section 3 , and also for the survey forecasts in the remainder of this section. Note that if we are able to predict GDP second and third estimates more accurately than the benchmark, we are effectively reducing the data uncertainty surrounding real-time policy and economic decision-making.

Before the announcement of 'market moving' economic data, business websites such as Bloomberg 
(www.bloomberg.com) and Econoday (www.econoday.com) provide the 'consensus forecast' of the pre-announcement value of output growth. The consensus forecasts are the medians of the forecasts made on the Friday before the announcement. These determine the forecast horizon we consider. Aggarwal, Mohanty and Song (1995) and Hess and Orbe (2011) have evaluated survey forecasts of the releases computed by the MMS (International Money Market Services). Our preliminary results suggest the choice of survey provider matters little - the accuracy of the forecasts for overlapping periods is generally similar. (We compare MMS, Bloomberg, Econoday and Action Economics). We use the survey median provided in the Econoday report for the advance, second and third estimates of US GDP growth (notwithstanding the pre-eminence of Bloomberg with practitioners). This covers 2001:M1 to 2013:M12, and so includes both the 2001 and the 2008-9 recessions, and the post Financial Crisis recovery period.

Figure 1 presents the forecast errors from predicting the second and the third release of US GDP growth. For the survey forecasts, the forecast errors are the released estimates minus the forecasts of these quantities. The same is true for the no-change forecasts, but in this case the forecast errors are also the revisions to the estimates: for the second estimate, for example, the no-change forecast is equal to the advance estimate. In the figure, the dates refer to the release dates, for example, 2005M2 refers to the second estimate of GDP growth for 2004Q4. No-change forecast errors for the second release are in the range is -2.5 to $1.5 \%$, but are smaller for the third release, with a range of -0.6 and $0.6 \%$. Hence the revisions between the advance and second estimates are reasonably large, given that the average GDP growth rate is $3 \%$ (computed with latest-available vintage data for the period 1985-2007), while the revisions between the second and third estimates are markedly smaller. The improvements offered by the professional forecasters for the second release are evident from the figure, and reflect the accumulation of information over the month or so since the earlier estimate. But equally clear is that their forecast errors for the third release are similar to those of the no-change forecasts. It may of course be the case that forecasters put less effort into forecasting the typically small revisions between the second and third estimates, compared to the revisions between the advance and second estimates. 
We use the root mean squared forecast error (RMSFE) to measure forecast performance. Table 1 records the RMSFEs of no-change forecasts as benchmarks against which the survey forecasts can be assessed. For completeness, we also report the accuracy of forecasts of the first release, using last quarter's final estimate as the benchmark: $\hat{y}_{t}^{t+1 / 3}=y_{t-1}^{t}$. Table 1 includes a test of the null of equal forecast accuracy. The alternative hypothesis is that the no-change benchmark is less accurate than the survey median (i.e., a one-sided test). This is the $t$-statistic of Diebold and Mariano (1995). Rejections at 1, 5 and 10\% significance levels are indicated by ${ }^{* * *},{ }^{* *}$ and *, respectively.

As expected, the survey forecasts are much more accurate for the advance estimate. But the results also indicate sizeable improvements in accuracy for the second release of GDP growth. The RMSFE is a half of that for the no-change benchmark. By contrast, the third estimate is not predicted any more accurately by the survey forecasters than if we were to assume no revision to the second estimate, consistent with the visual impression provided by Figure 1.

We investigate possible dependence of the results on the business cycle phase (see, e.g., Swanson and van Dijk (2006)) by evaluating forecasts separately for observations that fall in expansions and contractions. The split is based on the observation date as determined by the NBER business cycle chronology. The results in Table 1 indicate that the survey forecasts of the third release are equivalent to the no-change forecasts independently of the business cycle phase. In contrast, the survey forecasts of the second release record a larger reduction in RMSFE relative to the no change during contractions. Second release estimates are also more variable during contractions (compare the no-change RMSFEs for second estimates across phases). In short, the first revision (i.e., the second release) is both larger and relatively more predictable using survey forecasts during contractions. 


\section{$3 \quad$ Using Forecasting Models to Predict Revised Estimates}

The results in the previous section show that survey forecasts are significantly more accurate than no-change forecasts for the second release of GDP growth but not for the third release. In this section we consider whether forecasting models that use monthly economic indicators and daily financial indicators are more accurate than no-change forecasts for the second and third estimates of US GDP. All the data we use was available to the professional forecasters at the time they revealed their forecasts to the survey.

We use monthly vintages of US real GDP from 1966:M2 up to 2014:M1 from the Real-Time Dataset for Macroeconomists (RTDSM) of the Philadelphia Fed (see Croushore and Stark (2001)) to estimate the forecasting models. The RTDSM contains the data available at the middle of each month. Because early releases are normally published at the end of the month, we reschedule the real-time data set such that the first, second and third monthly vintages within a quarter contain the releases of, respectively, the advance, the second and the third estimates.

We assess which information is useful to predict early revisions (namely, the second and third estimates) in a real-time out-of-sample forecasting exercise. In-sample evaluations (such as Aggarwal et al. (1995), amongst others) may be misleading, especially if there are parameter instabilities. Against this, out-of-sample evaluations require longer spans of historical data because separate in-sample estimation and out-of-sample forecast periods need to be defined, but nevertheless we choose to conduct an out-of-sample evaluation. We evaluate forecasts from autoregressive models in section 3.1, from models with monthly economic indicators in section 3.2, and from models with daily financial data in section 3.3.

Table 2 summarizes the forecasting models used in this paper for ease of reference, with detailed explanations in what follows. We aim to forecast the second and the third estimates, that is, $y_{t}^{t+v}$ for $v=2 / 3,1$. Note that $t=1,2, \ldots$ in quarters, varying for both vintages (superscripts) and observations (subscripts). All forecasting models use the revision $y_{t}^{t+v}-y_{t}^{t+v-1 / 3}$ as the dependent variable for reasons explained in section 3.1. 
We present a real-time analysis of forecasting early GDP monthly releases. The out-of-sample periods match the release dates covered by the survey (2001:M2-2013:M12). At each new forecast origin we re-estimate each model with an expanding number of observations obtained from the real-time dataset available at the time the forecast was made. As in section 2 , we provide results for the whole period and also the split by business cycle phase.

We assess whether model forecasts are more accurate than the random walk using the $t$-test of Diebold and Mariano (1995) (DM), assuming quadratic loss. An alternative test for nested models is the encompassing statistic of Clark and West (2007) (CW), which makes an allowance for the effect of parameter estimation uncertainty (in estimating the nesting model). Effectively the CW test assumes that we have an infinitely large sample, that is, that we are able to use the population values of the model's parameters to generate forecasts. The DM approach tests whether the model is more accurate than the random walk allowing that the model needs to be estimated, and unlike $\mathrm{CW}$, will only reject the null when the mean squared forecast error of the model's forecasts is smaller than that of the random walk. Thus the DM approach seems preferable for our purposes.

\subsection{Information from Past Vintages}

We start by considering forecasting models with an information set restricted to past data in the US real GDP real-time dataset. If past data vintages of output growth help predict the second and third estimates in comparison with the no-change forecast benchmark, then revisions at least in part embody a reduction in noise or measurement error.

The first panel of Table 2 summarizes the five forecasting models. The first model assumes that data revisions are serially uncorrelated, possibly with a non-zero mean. The second model adds an autoregressive term related to the 'spillover effect': see e.g., Jacobs and van Norden (2011). The third model allows revisions to depend on the value of the earlier release. Similar regressions are commonly used to test whether revisions are news. If $\beta_{0}=\beta_{1}=0$ then data revisions are unpredictable (news) as defined by Mankiw and Shapiro (1986). Note that by comparing the outof-sample forecasting performance of these models with the no-change forecast, we are assessing 
the out-of-sample predictability of data revisions. If the DM test rejects the null, we conclude that revisions are not pure news.

Clements and Galvão (2013) have shown that models of multiple data vintages are able to predict quarterly data revisions to output growth and inflation by exploiting information on past revisions, and in particular, the annual revisions which take place in the third quarter of each year. The fourth model in the first panel of Table 2 is a 'vintage-based' model: a simplified singleequation version of their model (see also Koenig, Dolmas and Piger (2003), and Croushore (2011a) for a recent survey of forecasting with data vintages). We experiment with $q=5,14$, where $q$ is the number of lags.

Swanson and van Dijk (2006) report that the biases of the revisions to industrial production depend on the state of the business cycle. To capture possible business cycle asymmetric effects, we consider a threshold specification that allows the response of the revision to the earlier release to depend on the sign and size of the earlier release: this is the fifth model in Table 2, a 'threshold model'. Note that in the specification of this model $I()$ is an indicator function (so $I(x)=1$ when $x$ is true, and $I(x)=0$ otherwise) and $c$ is the value of the threshold. The threshold is jointly estimated with the slope parameters by conditional least squares. The estimation employs a grid search for the threshold value $c$ based on the restriction that each regime must have at least $15 \%$ of the observations (see, e.g., Hansen (2000)).

Table 3 presents the ratios of the RMSFEs of each of the 5 models to that of the no-change benchmark. By and large, there is little indication that any of these 'own-information' past vintage models improves on the no-change benchmark, and in particular, there is no evidence to support the use of a threshold specification. Broadly, these findings are in agreement with the literature suggesting there is limited predictability of earlier revisions to US GDP growth (as, for example, Mankiw and Shapiro (1986) and Faust et al. (2005)). 


\subsection{Information from Monthly Economic Indicators}

As discussed, early monthly estimates of real GDP are based on extrapolations, and subsequent releases incorporate new information as it becomes available (see e.g., Landefeld et al. (2008)). Forecasters might be able to predict upcoming data releases by using the new information published since the previous release (either the advance estimate, or the second) but before the target release (respectively, the second, or the third) is announced. We consider monthly economic indicators which are sometimes categorized as 'market moving' (see, e.g., Econoday, www.econoday.com) reflecting their perceived importance as indicators of the state of the economy. The variables included in this study are listed in Table 4, along with the data sources, and their timeliness (or delay), which we discuss below. Their importance derives from their correlations with GDP and its components, and their early availability. Our choice of variable is also determined by the availability of a real-time set with monthly vintages over a long period.

Our monthly indicators include industrial production and employment. Market participants in general perceive the announcements of these variables as carrying information on subsequent GDP growth announcements. The nonfarm payroll announcement in particular receives much media attention. Retail sales is justified as an indicator of current consumption, and the production manufacturing index (NAPM) and durable good orders measure current aggregate production. An alternative measure of consumer spending is provided by the University of Michigan Consumer Sentiment Index, which is generally regarded as a leading indicator, as opposed to a coincident indicator. We also include two housing activity measures, housing starts and new home sales, as well as the CPI as a measure of inflation (the GDP deflator is released at the same time as GDP, and so cannot be used as a predictor). Finally, we consider the monthly trade balance computed from the Balance of Payment accounts. An additional motivation to include this variable is that exports and imports are GDP components subject to mean absolute revisions (between the initial monthly estimates and the latest-available estimates) which are three or four times larger than for personal consumption expenditures, even though their proportion of real GDP they account for is 
small (see, e.g., Fixler et al. (2014, Table 1, p.5)).

The majority of the variables in Table 4 are subject to revision. This means that for such variables we typically have $(i)$ data published after the announcement of the current GDP estimate, including new observations and revisions to the past data; and ( $i i)$ values and observations already available before the announcement of the current GDP estimate ('past' information). We can organize the new information into: 'new revision', 'new observation' and 'updated observation'. By comparing the relative forecasting accuracy of models which exploit new, updated and past information, we can assess the efficiency of early GDP releases for later releases, and discover which information helps predict subsequent GDP releases.

To illustrate the use of the different types of information, consider the five indicators (which include industrial production and employment) which are published with a delay shorter than 21 days from the end of the observational month. Assume that $X_{t}$ refers to the observation in the last month of quarter $t$, while $X_{t-2 / 3}$ is the observation in the first month of quarter $t$. We employ quarterly differences of the monthly variables, that is, $x_{t}^{t+v}=\left(X_{t}^{t+v}-X_{t-1}^{t+v}\right)$. The monthly revision is given by $x_{t}^{t+v}-x_{t}^{t+v-1 / 3}$. Suppose we wish to predict the second estimate of GDP in quarter $t$, namely $y_{t}^{t+2 / 3}$. The information set consists of the advance GDP estimate, $y_{t}^{t+1 / 3}$, as well as the second-month vintage for $x$, comprising the first estimate of $x$ for the month following the reference quarter $t\left(x_{t+1 / 3}^{t+2 / 3}\right)$, the second estimate of $x_{t}\left(x_{t}^{t+2 / 3}\right)$ and revised values for earlier months, as well as data in the first-month vintage for $x_{t}$ and earlier periods, etc. That is, $\left\{y_{t}^{t+1 / 3} ; x_{t+1 / 3}^{t+2 / 3}, x_{t}^{t+2 / 3}, \ldots ; x_{t}^{t+1 / 3}, x_{t-1 / 3}^{t+1 / 3}, \ldots\right\}$.

The 'New Revision' regression model uses the published revision of the indicator $x_{t}^{t+2 / 3}-x_{t}^{t+1 / 3}$ to predict $y_{t}^{t+2 / 3}-y_{t}^{t+1 / 3}$. (This model and the others discussed in this section are given in the second panel of Table 2). The 'New Observation' model uses $x_{t+1 / 3}^{t+2 / 3}$ to predict $y_{t}^{t+2 / 3}-y_{t}^{t+1 / 3}$. The 'Updated Observation' model uses $x_{t}^{t+2 / 3}$ (as opposed to the revision, $x_{t}^{t+2 / 3}-x_{t}^{t+1 / 3}$ ). We also consider the use of 'Previous Release' data, i.e., the use of $x_{t}^{t+1 / 3}$ to predict $y_{t}^{t+2 / 3}-y_{t}^{t+1 / 3}$. That is whether data at the time of the publication of the first release $\left(x_{t}^{t+1 / 3}\right)$ helps predict the revision to GDP. 
As shown in Table 2, this illustration of predicting the second estimate generalizes to predicting the third estimate. For example, the New Revision model uses $x_{t}^{t+1}-x_{t}^{t+2 / 3}$ to predict the third estimate, $y_{t}^{t+1}-y_{t}^{2 / 3}$; the Previous Release model uses $x_{t}^{t+2 / 3}$ to predict $y_{t}^{t+1}-y_{t}^{t+2 / 3}$, and so on.

For the three indicators published with a longer delay, $x_{t}^{t+2 / 3}$ indicates a first estimate (rather than a second estimate), and the models have to be adapted accordingly. For example, the New Revision model is only applicable for forecasting the third release of GDP $(v=1)$. The Updated Observation is the initial release of the indicator for predicting the second release of output growth, but is the revised value otherwise. The New Observation regression model (employing $x_{t+v-1 / 3}^{t+v}$ as a predictor) is only feasible for the five indicators published with a short delay.

Note that the results of the Previous Release model have a bearing on whether data estimates are efficient (or whether subsequent revisions are predictable). If Previous Release model forecasts are significantly more accurate than no-change forecasts, early GDP estimates are not efficient since they do not use all available information. If data revisions are not predictable from 'past information', then revisions are typically classified as news (see, e.g., Croushore (2011b)). Note that in contrast with much of the literature, the use of a short forecast horizon of up to one-week-ahead allows for the possibility that a given release may be news, in the sense of being unpredictable based on data at the time of the earlier release, but may still be predictable from more recent information: the new revisions, observations, or updated information. By exploiting economic releases between the current and target GDP release, we consider whether the target release is predictable up to one-week in advance.

For the two survey-based variables in Table 4 that are not subject to revisions and are published with short delays (NAPM and consumer confidence), we apply the New Observation model with $x_{t+v-1 / 3}$ to exploit new information, and the Previous Release model with $x_{t+v-2 / 3}$ to consider past information.

The results for using monthly economic indicators as predictor variables are given in Table 5 . We consider all the variables taken together (first two panels of Table 5), as well as the predictive power of the indicators one-by-one (third and fourth panels). Given the poor performance of models 
with autoregressive components (see Table 3) we omit such terms, while non-zero mean revisions are accommodated by the inclusion of intercepts in the regressions. We record RMSFE ratios of the models using each type of information against the benchmark. (The second panel of Table 2 summarizes the models we estimate.) The first panel of Table 5 shows the results for the second GDP estimate, and the second panel the results for the third estimate (using all the indicators). For the second estimate, both the Updated Observation and Previous Release model result in statistically significant improvements in accuracy (at the 10\% level). The usefulness of both these types of information is greater in contractionary quarters. For the third estimate, the only gains are from the use of Previous Release survey data, and then only in contractionary periods. Results for each individual predictor in the third and fourth panels of Table 5 suggest little is lost by considering all the variables together.

In summary, there is some evidence of predictability during recessions for both releases, using economic indicators, and the second estimate is predictable overall from both new information (the Updated Observation model) and past information (the Previous Release model). However, while survey forecasts of second estimate GDP growth improve on the benchmark by $50 \%$ on RMSFE, for the third estimate the model-based gains (over the no-change forecast) are markedly less (and tend to be realized in recessions).

\subsection{Information from Daily Financial Variables}

Our third information set consists of daily financial variables. That financial variables may have predictive content for growth data revisions is suggested by Andreou, Ghysels and Kourtellos (2013), who show daily financial indicators help to nowcast revised values of GDP growth. They find short-term interest rates, bond spreads and stock returns are among the indicators with the best forecasting accuracy for output growth one-quarter-ahead. Secondly, Gilbert (2011) argues that on days that advance estimate announcements are made, equity returns respond to incorporate information on expected future data revisions to measures of economic activity such as nonfarm payroll employment and output growth. This implies that equity returns (observed during the first 
month of the current quarter, $t+1 / 3)$ might help predict the second and third estimates released in $t+2 / 3$ and $t+1$.

We use Mixed Data Sampling (MIDAS) regressions to exploit the information in daily financial variables for predicting the quarterly data releases (see for example the review article by Andreou, Ghysels and Kourtellos (2011) on MIDAS). The MIDAS regression is described in the third panel of Table 2. The lag operator is applied to daily data, and we assume that there are $m=60$ daily observations per quarter. The number of daily lags is set to $K$. The weighting function $w_{j}(\boldsymbol{\theta}, K)$ is a beta function with two parameters in the vector $\boldsymbol{\theta}$. The aggregation weights $w_{j}(\theta, m)$ sum up to 1 to guarantee the identification of the slope parameter $\alpha_{1}$. Galvão (2013) shows that beta functions work better than an exponential function when $m$ is large. The parameters of the weighting function are jointly estimated with the slope and intercept parameters by nonlinear least squares. When using information up to $t$, the lead parameter $l$ is set to $v$, and $K=60$, that is, we use all the daily data from the observation quarter $t$. When using information up to $t+1 / 3$, $l=1 / 3$ for $v=2 / 3$, and $l=2 / 3$ for $v=1$, while in both cases $K=20$, so only data from the month of the first GDP announcement is considered.

Instead of estimating the function to aggregate high frequency data, we can also assume flat aggregation (equal weighting) and set $w_{j}(\boldsymbol{\theta}, K)=1 / K$ for all the daily lags, giving the 'Linear' model of Table 2 .

Galvão (2013) suggests that regime changes in the slope parameters may also affect the accuracy of output growth forecasts. The slope coefficients in models which use financial variables to predict output growth may shift because of market regimes (bull/bear) and monetary policy regimes (loose/tight). Therefore, we also employ the Smooth Transition MIDAS (STMIDAS) regression as a forecasting model to extract information from daily financial variables. The MIDAS model is modified such that the slope parameters are weighted by a logistic function. The values of the logistic function (between 0 and 1 ) at each point in time depend on the difference between the aggregated high frequency data and a threshold $c$. The smoothness of the function depends on the parameter $\gamma$. The STMIDAS regression is described in the last row of Table 2. Note that 
the parameters of the aggregation function $w_{j}(\boldsymbol{\lambda}, m)$ of the transition function may differ from the parameters of the aggregation function of the indicator as a predictor $\left(w_{j}(\boldsymbol{\theta}, m)\right)$.

We need a long historical sample on each financial variable to estimate these models for out-ofsample forecasting. This restricts us to the 5 financial variables described in Table 6 , with data from the early 60's for all the variables other than the Baa spread. The empirical results of Andreou et al. (2013) suggest the use of stock returns (both SP500 and DJIA) and the short-rate as predictors of economic activity variables. Gilbert (2011) uses the SP500 to capture the market reaction to the release of the advance estimate of GDP growth. As well as these variables, we include a measure of the interest rate spread (computed as the difference between the 10-year Treasury bond and a 3-month Treasury bill), as suggested by Galvão (2013). We also include the short rate as well, allowing the model to capture the level and slope of the yield curve (as suggested by the findings of Wright (2006)). Finally, we include the Baa spread, defined as Moody's BAA yield minus the 10-year Treasury Rate. This is motivated by the evidence in Gilchrist and Zakrajsek (2012) on the predictive power of corporate bond spreads for economic activity.

We experimented with multiple variable models, as indicated by the notation in Table 2 . We included all financial variables together, as well as a variant that included just the level and slope of the yield curve, and finally a model including just the two equity variables: see the first two panels of Table 7. Results are given only for the MIDAS and Linear models, as STMIDAS models did not fare well given the proliferation of parameters when there is more than one variable. Results for STMIDAS for single financial predictors (and for the MIDAS and Linear models) are given in the third and fourth panels of Table 7 .

Table 7 presents the RMSFE ratios with respect to the benchmark. It also compares the accuracy of models using daily data through quarter $t(K=60)$, with models with daily data for the first month of the quarter (i.e., the month of the first announcement, $t+1 / 3, K=20$ ), and with models using daily data up to the day before the second or the third release announcements. This last comparison is restricted to observations from 1975 onwards, for which we have the precise dates of the GDP (or GNP) releases. It is run for $K=60$ and the results are presented in the last 
columns of Table 7 (indicated by ' $x_{t+d b}$ ').

The measures of relative accuracy show that equity returns from the month of the first announcement have statistically significant predictive power for both releases. (This is confirmed by the results for the individual indicators). The equity returns over this period capture any effect that the announcements of the advance GDP estimate and 'market-moving' economic variables may have had on the stock market. The table also shows that daily data for the period beyond the first

month (included in the information set available with ' $x_{t+d b}$ ' for $y_{t}^{t+1}$ ) is of no value for predicting the data revision revealed by the announcement of the third estimate. Daily stock returns tend to have a significant effect during expansions but not during contractions. The MIDAS model is generally as good or better than the Linear model.

It is possible that the predictive content of equity returns stems solely from their embodying news on the economic indicators released during the month. To see whether this is the case, in Table 8 we consider the incremental effect in terms of forecast accuracy of adding the equity variables to the best forecasting models using monthly economic indicators. From Table 5, we found the Updated Observations model provided the best forecasts of the second estimate, and the Previous Release model the best forecasts of the third GDP estimate. We report the RMSFEs for these models in Table 8, and then the effect of including daily returns in these models via a MIDAS regression with a beta weighting function, and with all the parameters being estimated jointly by nonlinear least squares. Statistically significant reductions of RMSFE from the inclusion of daily financial variables are detected for predicting the third release of GDP growth during both business cycle phases, and for predicting the second release during recessions. The results in Table 8 indicate that equity returns contain additional information to that in the economic variables.

\section{Data Revisions and Equity Markets}

The literature has identified two main problems with estimating the effects of macroeconomic surprises on equity returns. First, Rigobon and Sack (2008) argue that if survey forecasts are a 
noisy proxy for market expectations, the estimates of the impact of macroeconomic surprises on asset returns will be attenuated. Second, 'good news may be bad news for stock returns'. An unexpected increase in growth may presage a tightening of monetary policy to allay fears of a build up of inflationary pressure. In general, this is solved by considering the impact of surprises during expansions and contractions separately (see, e.g., McQueen and Roley (1993)). Good news may have negative effects on stock markets during expansions and positive effects during contractions.

In this section we address both of these issues. We look at the effect of surprises emanating from the second and third GDP releases on daily equity returns, allowing differential impacts across business cycle phases by running separate regressions for recessions and expansions. For market expectations we use both the Econoday survey median (following Andersen et al. (2003)) and a model-based measure motivated by our earlier results. We also assess the evidence for the finding of Gilbert (2011) that investors respond to the information the GDP release carries about the true value of GDP. As well as the replication of the Gilbert (2011) event study on our dataset using both SP500 and DJIA returns, we also explicitly decompose future revisions into an expected and a 'surprise' component to further investigate the response of the stock market to information about the final value conveyed by the announcement-day release. This expected/surprise decomposition, together with measures of market expectations of forthcoming GDP releases that draw on daily stock returns, help shed additional light on how GDP revision announcements affect the equity market.

\subsection{The Impact of Announcement Surprises}

Our empirical results suggest that the model forecasts are superior to the survey forecasts for the third release, although the survey forecasts perform better for the second release. However, a combination of model and survey forecasts might perform even better, and potentially provide a superior measure of market expectations. We calculate regression-based forecast encompassing tests (see e.g., Clements and Harvey (2009) for a recent review) to investigate the potential for combination, but find that survey forecasts encompass model forecasts for the second release, in 
both business cycle phases, and that the model forecasts encompass the survey forecasts for the third release. This supports the use of the model forecasts as a proxy for market expectations for the third release to lessen the impact of error in the expectations measure. We report results using both survey and model forecasts for the two releases. The model forecasts are generated from a MIDAS regression which use the 'best' model with monthly economic variables for the release in question, combined with daily stock returns (SP500) for the month of the initial release of GDP (see section 3.3 and Table 8).

We estimate the effects of surprises in GDP release announcements on daily stock returns (measured by the SP500 and the DJIA) on the day of the announcement. Preliminary results suggest that the size of the effect is similar for both measures. Given the relatively small sample for this event study (52 quarterly observations), we estimate the two equations by pooled ordinary least squares to obtain a more accurate estimate of the effects of surprises.

Announcement surprises are standardized and measured as:

$$
S_{t, k}^{t+v}=\frac{y_{t}^{t+v}-\hat{y}_{t, k}^{t+v}}{s t d\left(y_{t}^{t+v}-\hat{y}_{t, k}^{t+v}\right)},
$$

where $\hat{y}_{t, k}^{t+v}$ is the forecast using method $k$ (either a model or professional forecasters consensus) of the second release (if $v=2 / 3$ ) or of the third release (if $v=1$ ). Let $r t_{t+v, i}$ denote the return to stock index $i$ on the day of the announcement of a revised GDP figure. Then we evaluate the impact of data revision surprises by estimating:

$$
\operatorname{ret}_{t+v, i}=\beta_{0}+\beta_{1} S_{t, k}^{t+v}+\varepsilon_{t, i}
$$

where $i \in\{$ SP500, DJIA $\}$ and $t$ runs over the 52 events.

Table 9 reports the estimates of the slope coefficients $\left(\beta_{1}\right)$ in equation $(1)$, and the $R^{2}$ statistics. The results employing the survey forecasts as market expectations (in the top panel) confirm previous results in the literature (e.g., Gilbert (2011)) that third-release surprises have no impact 
on stock returns. Second-release surprises are shown to have an impact on stock returns, but only during recessions. The positive sign of the coefficient implies that 'good news' has a positive impact on the stock market during recessions. These results could be interpreted as suggesting that equity markets pay more attention to data revision releases during recessions, when their relative size and predictability is larger (see section 2).

The use of the model-based measure of market expectations increases the magnitude of the estimated response of returns to second-release surprises (see the second panel of Table 9). The size of the response to third-release surprises triples, for all observations (i.e., when we do not differentiate by business cycle phase). Although the coefficient is not significant at conventional levels, this may simply reflect the small sample size. The increased estimated response is consistent with the greater accuracy of the model forecasts for the third release, and with these forecasts providing better proxies of market expectations.

\subsection{The Impact of Future Revisions}

Gilbert (2011) argues that investors 'respond to the information conveyed by the initial release about the correct value and not only its preliminary estimate'. Gilbert (2011) defines the 'total' surprise as the difference between the final value $\left(y_{t}^{t+\infty}\right)$ and the forecast of the announcement $\left(\hat{y}_{t, k}^{t+v}\right)$, which can be written (in our notation) as:

$$
T S_{t, k}^{t+\infty}=y_{t}^{t+\infty}-\hat{y}_{t, k}^{t+v}=\underbrace{\left(y_{t}^{t+\infty}-y_{t}^{t+v}\right)}_{R_{t}^{t+\infty}}+\underbrace{\left(y_{t}^{t+v}-\hat{y}_{t, k}^{t+v}\right)}_{S_{t, k}^{t+v}}
$$

that is, as the (non-standardized) revision $R_{t}^{t+\infty}$ plus the (non-standardized) 'announcement surprise' $S_{t, k}^{t+v}$ (which we will continue to refer to as the surprise). By including a standardized version of $R_{t}^{t+\infty}$ in the regressions of section 4.1 (e.g., $\left.\widetilde{R}_{t}^{t+\infty}=R_{t}^{t+\infty} / \operatorname{std}\left(R_{t}^{t+\infty}\right)\right)$ we are able to gauge the response of announcement-day returns to future revisions, as well as to announcement surprises $\left(S_{t, k}^{t+v}\right)$. The first of these terms allows returns to respond to the true value. 
In the first panel of Table 10, we replicate Gilbert's regression using our panel dataset, and report results for announcement surprises calculated using survey-consensus forecasts, and including in the regression the actual revisions, $R_{t}^{t+\infty}$. We approximate $y_{t}^{t+\infty}$ using data from the 2013M12 vintage, and consequently shorten our sample of data releases. We remove the last two years so that the 2013M12 vintage can be used to provide a reasonable measure of future revisions, $R_{t}^{t+\infty}$.

Our results for second-release announcements match Gilbert (2011, Table 8 and 9, p.128). Future revisions have a significant negative effect on stock returns during recessions, but no (significant) effect during expansions. However, our results for third-release announcements differ. Gilbert finds a significant negative effect of third-release revisions on returns during recessions, and a positive effect in expansions, whereas we only find a significant effect in contractions, and the effect is positive.

If we instead measure announcement surprises $S_{t, k}^{t+v}$ using model-based forecasts (see the second panel of Table 10), we now find evidence of a significant response of equity markets to surprises in third-release announcements. This is consistent with the superior accuracy of the model forecasts (relative to the survey forecasts), as discussed in section 4.1, which provide more accurate estimates of the surprises experienced by the market. Future revisions to third releases continue to have a significant effect, as when survey forecasts are used to define surprises, but future revisions to second-releases no longer have an impact.

These results imply that, controlling for announcement day surprises, upward revisions in thirdrelease GDP figures boost equity markets during recessions. To further investigate this issue, we decompose the revisions term $R_{t}^{t+\infty}$ in (2) into the expected revision, ER, and the surprise revision, SR. That is,

$$
\underbrace{\left(y_{t}^{t+\infty}-y_{t}^{t+v}\right)}_{R_{t}^{t+\infty}}=\underbrace{\left(E_{t+v} y_{t}^{t+\infty}-y_{t}^{t+v}\right)}_{E_{t+v} R_{t}^{t+\infty}}+\underbrace{\left(y_{t}^{t+\infty}-E_{t+v} y_{t}^{t+\infty}\right)}_{S R_{t}^{t+\infty}} .
$$

An issue with the use of $R_{t}^{t+\infty}$ to measure future revisions is that the true value $y_{t}^{t+\infty}$ will not be realized until many years later, and will include benchmark revisions and changes in the methodology of data collection and compilation, which will be unforeseen at period $t$. One might suppose 
that the announcement-day return would only respond to the predictable revision, $E_{t+v} R_{t}^{t+\infty}$, i.e., how far the current release is from the predicted true GDP value. We consider regressions which include the announcement day surprises $S_{t, k}^{t+v}$ (as in section 4 ), as well as both $E_{t+v} R_{t}^{t+\infty}$ and $S R_{t}^{t+\infty}$, as a way of determining whether the expected revision or the actual future revision drives announcement-day returns. In population, at least, if the coefficient on the surprise revision is not significantly from zero, the results would favour the expected revision. In practice of course we have a relatively small sample of data for teasing out the importance of these different factors.

We require that our estimate of $E_{t+v} y_{t}^{t+\infty}$ - the forecast of the true value - accurately reflects the unknown market expectations of the true values. These expectations are generated by vintage-based vector autoregressive models of real GDP growth (as in Clements and Galvão (2013)) assuming that the true value $y_{t}^{t+\infty}$ is well approximated by the value in the quarterly vintage released 14 quarters after the observational quarter. The model is estimated on quarterly vintages of data up to an including the $t+v$ vintage, and exploits the predictive content of past vintages for future vintages. The results in Table 3 suggest that a simplified version of this approach was the only autoregressive specification able to improve upon the no-change forecast, at least during recessions.

The third panel of Table 10 records the results of regressing returns on (standardized versions of) $S_{t, k}^{t+v}, E_{t+v} R_{t}^{t+\infty}$ and $S R_{t}^{t+\infty}$. We find that neither expected or surprise future revisions have significant effects on stock returns for second releases.

The evidence that future revisions affect equity markets on the day of the third GDP release is confirmed. The finding that the expected and surprise future revisions are of the same sign and a similar magnitude indicates that third-release announcement-day returns respond to the actual future revision (as opposed to the expected future revision). This could be explained by markets knowing more about upcoming third releases than is indicated by our model forecasts. That is, part of the 'surprise' future revision, given our forecasts, may in fact be included in market participants' forecasts of future revisions.

In general, the publication of better than expected early GDP figures provides a boost to equity markets during contractionary periods. And if the market expects future upward revisions 
(especially to the third release figures), the effects are enhanced. By and large, the use of modelbased expectations provides more evidence that equity markets react to data revisions than when survey forecasts are used to measure market expectation, principally for third releases. In our analysis, the models are used to measure market expectations of the upcoming announcement and of future revisions to the announced value.

\section{Conclusions}

Data revisions clearly contribute to the uncertainty about the current state of the economy, and about the current conditions of macroeconomic fundamentals, which in turn may affect economic activity. An early contribution was Oh and Waldman (1990), who considered the macroeconomic effects of 'false' announcements (see also Oh and Waldman (2005)), and argued that an upbeat estimate of the current state of the economy which was subsequently revised down would lead to stronger output growth than would otherwise have transpired (with the reverse being true of an ex post pessimistic assessment). Rodriguez-Mora and Schulstad (2007) find that first announcements of GDP growth are a more important determinant of subsequent actual GDP growth than the true value of GDP growth in the earlier period (see also Clements and Galvão (2010)). The importance of expectational errors for business cycle fluctuations has a long history, as indicated in the cited papers. A recent strand of the literature has considered the role of 'noise shocks' in generating aggregate fluctuations (Lorenzoni (2009), Blanchard, L'Huillier and Lorenzoni (2013)). Blanchard et al. (2013) estimate that noise shocks account for more than half of the forecast-error variance of output growth at short horizons: changes in the fundamentals explain a smaller proportion of this variance. Measurement errors in initial estimates of GDP and related macro variables (such as productivity growth) may constitute one source of noise shocks, and as such the extent to which subsequent revisions are predictable may have important implications for business cycle analysis.

Our empirical investigation focuses on determining the predictability of early data revisions to US output growth at short horizons, namely, the predictability of the revisions revealed by the 
release of the second and the third estimates of US GDP at horizons as short as one week. The horizon is determined by the nature of the survey forecasts for these releases, and we line up the data underlying the model-based forecasts to ensure our exercises are feasible in real time. We find that the survey forecasts of the second GDP release are far more accurate than the model-based forecasts, but that the survey forecasts of the third GDP do not draw on sources of information which could be tapped, and which might inform market expectations.

Our findings suggest that an economic agent seeking to reduce data uncertainty when taking decisions in real time ought to use survey forecasts for the upcoming second release, but would do better to forecast the third release with a model which combines information on economic indicators and equity returns from the month of the first release. A novel finding is that data revisions are forecastable at short horizons even when they add new information relative to an earlier release.

Studies of the impact of macro news on financial variables rely on market expectations being well approximated by the median forecast of a survey of professional forecasters (Rigobon and Sack (2008)). The use of the survey median as a proxy for the market expectation of the third release value of GDP is problematic if, as seems likely, market participants exploit all relevant information. We use models to measure market expectations of the upcoming announcement, and to generate expectations of future revisions (that is, between the announced value and the final or true value). We show that the publication of better than expected third-release GDP figures provides a boost to equity markets, and that if the market expects future upward revisions the effects, during contractions, are enhanced. This is a novel finding: equity markets respond to unanticipated news about the third GDP estimate, and not just to the advance and second estimates. But this only becomes evident when appropriate estimates of expectations are used: here model-based estimates of GDP releases which exploit daily returns data. 


\section{References}

Aggarwal, R., Mohanty, S., and Song, F. (1995). Are survey forecasts of macroeconomic variables rational?. Journal of Business, 68(1), 99-119.

Andersen, T. G., Bollerslev, T., Diebold, F. X., and Vega, C. (2003). Micro effects of macro announcements: real-time price discovery in foreign exchange. American Economic Review, 93, 38-62.

Andreou, E., Ghysels, E., and Kourtellos, A. (2011). Forecasting with mixed-frequency data, chapter 8. In Clements, M. P., and Hendry, D. F. (eds.), The Oxford Handbook of Economic Forecasting, pp. 225-246: Oxford University Press.

Andreou, E., Ghysels, E., and Kourtellos, A. (2013). Should Macroeconomic Forecasters Use Daily Financial Data and How?. Journal of Business 83 Economic Statistics, 31(2), 240-251.

Ang, A., Bekaert, G., and Wei, M. (2007). Do macro variables, asset markets, or surveys forecast inflation better?. Journal of Monetary Economics, 54(4), 1163-1212.

Aruoba, S. B. (2008). Data revisions are not well-behaved. Journal of Money, Credit and Banking, 40, 319-340.

Blanchard, O. J., L'Huillier, J.-P., and Lorenzoni, G. (2013). News, Noise, and Fluctuations: An Empirical Exploration. American Economic Review, 103(7), 3045-70.

Clark, T. E., and West, K. D. (2007). Approximately normal tests for equal predictive accuracy in nested models. Journal of Econometrics, 138, 291-311.

Clements, M. P., and Galvão, A. B. (2010). First announcements and real economic activity. European Economic Review, 54, 803-817.

Clements, M. P., and Galvão, A. B. (2012). Improving real-time estimates of output gaps and inflation trends with multiple-vintage VAR models. Journal of Business and $\mathscr{G}$ Economic Statistics, 30(4), 554-562. DOI: 10.1080/07350015.2012/707588.

Clements, M. P., and Galvão, A. B. (2013). Forecasting with vector autoregressive models of data 
vintages: US output growth and inflation. International Journal of Forecasting, 29(4), 698 714. DOI: 10.1016/j.ijforecast.2011.09.003.

Clements, M. P., and Harvey, D. I. (2009). Forecasting combination and encompassing. In Mills, T. C., and Patterson, K. (eds.), Palgrave Handbook of Econometrics, Volume 2: Applied Econometrics, pp. 169-198: Palgrave MacMillan.

Corradi, V., Fernandez, A., and Swanson, N. R. (2009). Information in the revision process of real-time datasets. Journal of Business and Economic Statistics, 27, 455-467.

Croushore, D. (2011a). Forecasting with real-time data vintages, chapter 9. In Clements, M. P., and Hendry, D. F. (eds.), The Oxford Handbook of Economic Forecasting, pp. 247-267: Oxford University Press.

Croushore, D. (2011b). Frontiers of real-time data analysis. Journal of Economic Literature, 49, $72-100$.

Croushore, D., and Stark, T. (2001). A real-time data set for macroeconomists. Journal of Econometrics, 105(1), 111-130.

Diebold, F. X., and Mariano, R. S. (1995). Comparing predictive accuracy. Journal of Business and Economic Statistics, 13, 253-263. Reprinted in Mills, T. C. (ed.) (1999), Economic Forecasting. The International Library of Critical Writings in Economics. Cheltenham: Edward Elgar.

Evans, M. D. D. (2005). Where are we now? Real-Time estimates of the Macro Economy. International Journal of Central Banking, 1. (2).

Faust, J., Rogers, J., Wang, S., and Wright, J. (2007). The high-frequency response of exchange rates and interest rates to macroeconomic announcements. Journal of Monetary Economics, 54, 1051-1068.

Faust, J., Rogers, J. H., and Wright, J. H. (2005). News and noise in G-7 GDP announcements. Journal of Money, Credit and Banking, 37 (3), 403-417.

Fixler, D. J., Greenaway-McGrevy, R., and Grimm, B. T. (2014). The revisions to GDP, GDI, and 
their major components. Survey of Current Business, August, 1-23.

Galvão, A. B. (2013). Changes in predictive ability with mixed frequency data. International Journal of Forecasting, 29, 395-410.

Garratt, A., Lee, K., Mise, E., and Shields, K. (2008). Real time representations of the output gap. Review of Economics and Statistics, 90, 792-804.

Gilbert, T. (2011). Information aggregation around macroeconomic announcements: Revisions matter. Journal of Financial Economics, 101, 114-131.

Gilbert, T., Scotti, C., Strasser, G., and Vega, C. (2015). Is the intrinsic value of macroeconomic news announcements related to their asset price impact?. Available at ssrn: http://ssrn.com/abstract=2598198 or http://dx.doi.org/10.2139/ssrn.2598198.

Gilchrist, S., and Zakrajsek, E. (2012). Credit Spreads and Business Cycle Fluctuations. American Economic Review, 102(4), 1692-1720.

Hansen, B. E. (2000). Sample splitting and threshold estimation. Econometrica, 68, 555-604.

Hess, D., and Orbe, S. (2011). Irrationality or efficiency of macroeconomic survey forecasts? implications from the anchoring bias test. SSRN eLibrary. http://ssrn.com/paper=1669587.

Jacobs, J. P. A. M., and van Norden, S. (2011). Modeling data revisions: Measurement error and dynamics of 'true' values. Journal of Econometrics, 161, 101-109.

Koenig, E. F., Dolmas, S., and Piger, J. (2003). The use and abuse of real-time data in economic forecasting. The Review of Economics and Statistics, 85(3), 618-628.

Landefeld, J. S., Seskin, E. P., and Fraumeni, B. M. (2008). Taking the pulse of the economy. Journal of Economic Perspectives, 22, 193-216.

Lorenzoni, G. (2009). A theory of demand shocks. American Economic Review, 99(5), 2050-84.

Mankiw, N. G., and Shapiro, M. D. (1986). News or noise: An analysis of GNP revisions. Survey of Current Business (May 1986), US Department of Commerce, Bureau of Economic Analysis, $20-25$. 
McQueen, G., and Roley, V. V. (1993). Stock prices, news, and business conditions. Review of Financial Studies, 6, 683-707.

Oh, S., and Waldman, M. (1990). The macroeconomic effects of false announcements. The Quarterly Journal of Economics, 105, 1017-1034. No. 4.

Oh, S., and Waldman, M. (2005). The index of leading economic indicators as a source of expectational shocks. Eastern Economic Journal, 31, 75-95. No. 1.

Orphanides, A. (2001). Monetary policy rules based on real-time data. American Economic Review, 91(4), 964-985.

Rigobon, R., and Sack, B. (2008). Noisy macroeconomic announcements, monetary policy, and asset prices. In Campbell, J. Y. (ed.), Asset Prices and Monetary Policy, pp. 335-370: University of Chicago Press.

Rodriguez-Mora, J. V., and Schulstad, P. (2007). The effect of GNP announcements on fluctuations of GNP growth. European Economic Review, 51, 1922-1940.

Swanson, N. R., and van Dijk, D. (2006). Are statistical reporting agencies getting it right? Data rationality and business cycle asymmetry. Journal of Business and Economic Statistics, 24, $24-42$.

Wright, J. H. (2006). The yield curve and predicting recessions. Finance and economics discussion series 2006-07, Board of Governors of the Federal Reserve System (U.S.).

Acknowledgments

Ana Galvão acknowledges support for this work from the Economics and Social Research Council [ES/K010611/1]. 
A) Forecasts of the Second Release

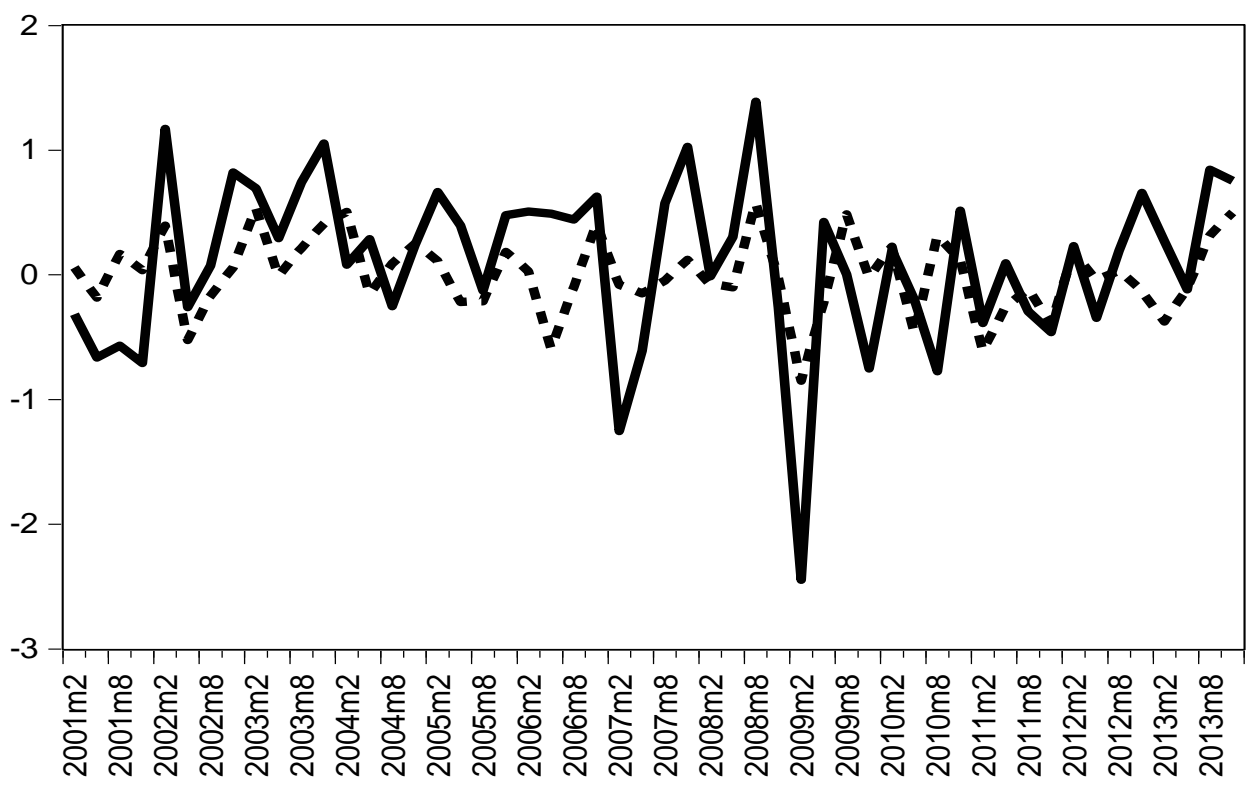

- - Professional Forecasters

No-change Forecast

B) Forecasts of the Third Release

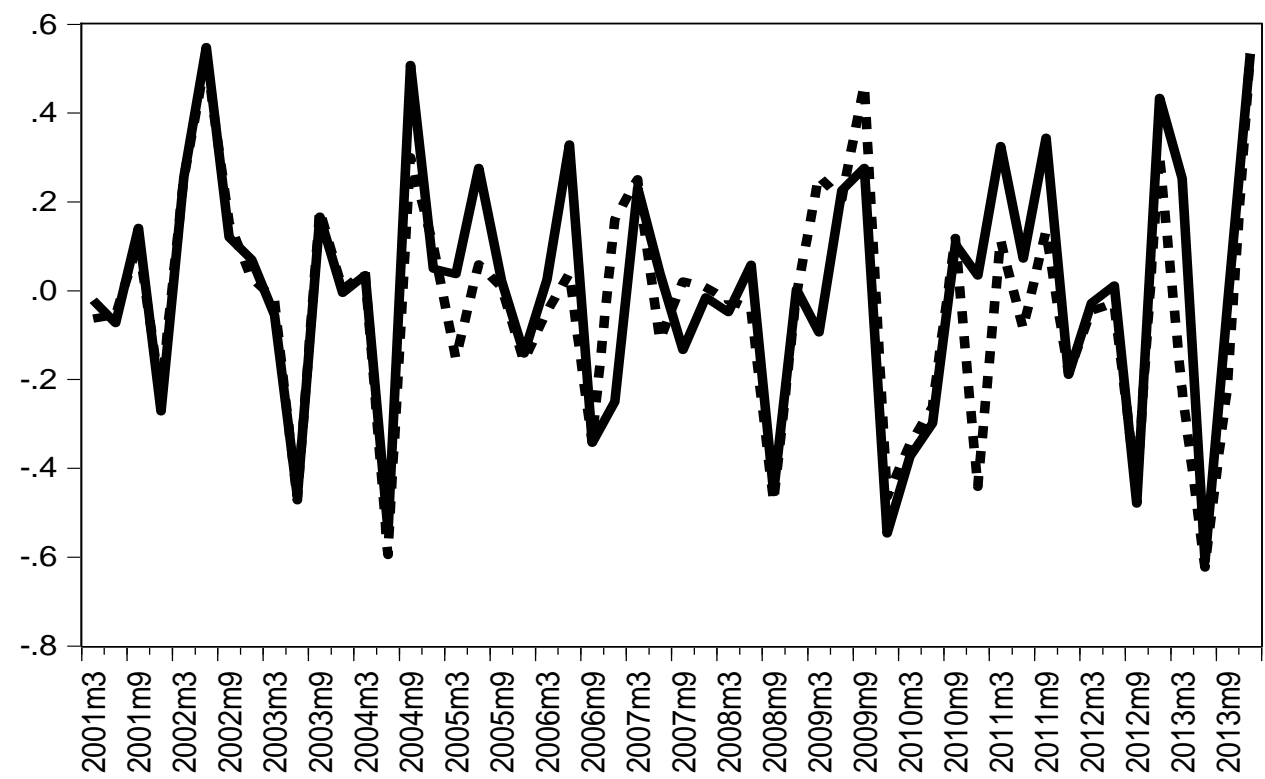

- - Professional Forecasters

No-change Forecast

Figure 1: Errors in Forecasting the Monthly GDP Releases. 
Table 1: Forecasting Accuracy of Survey Forecasts versus No-Change Forecasts, measured by RMSFE.

\begin{tabular}{l|c|c|c}
\hline \hline & $\begin{array}{c}\text { All } \\
(\mathrm{N}=52)\end{array}$ & $\begin{array}{c}\text { Contractions } \\
(\mathrm{N}=9)\end{array}$ & $\begin{array}{c}\text { Expansions } \\
(\mathrm{N}=43)\end{array}$ \\
\hline \multicolumn{4}{|c}{ Advance Estimate } \\
\hline No-Change Forecast & 2.220 & 2.221 & 2.219 \\
Survey Median [ratio] & $0.711[0.320]$ & $0.912[0.411]$ & $0.437[0.298]$ \\
Equal Accuracy t-stat & $4.851^{* * *}$ & $1.727^{* *}$ & $4.500^{* * *}$ \\
\hline \multicolumn{4}{c}{ Second Estimate } \\
\hline No-Change Forecast & 0.671 & 1.077 & 0.549 \\
Survey Median [ratio] & $0.310[0.462]$ & $0.413[0.383]$ & $0.284[0.517]$ \\
Equal Accuracy t-stat & $3.170^{* * *}$ & $1.741^{* *}$ & $4.046^{* * *}$ \\
\hline \multicolumn{4}{c}{ Third Estimate } \\
\hline No-Change Forecast & 0.279 & 0.237 & 0.287 \\
Survey Median [ratio] & $0.268[0.960]$ & $0.275[1.160]$ & $0.266[0.928]$ \\
Equal Accuracy t-stat & 0.801 & -1.174 & 1.374 \\
\hline \hline
\end{tabular}

Notes: The forecasts are of the data releases between 2001M1 and 2013M12.

Values in [] are the ratio of the Survey forecast RMSFE to the No-Change forecast RMSFE.

Statistical significance at the $1 \%$ level is indicated by $*$, at the $5 \%$ level by $* *$, and at the $10 \%$ level by $* * *$. 
Table 2: Forecasting Models for the Second and Third Releases $(v=2 / 3,1)$.

\begin{tabular}{|c|c|}
\hline & Autoregressive Models: \\
\hline Mean Revision & $y_{t}^{t+v}-y_{t}^{t+v-\frac{1}{3}}=\beta_{0}+\varepsilon_{t}$ \\
\hline AR model & $y_{t}^{t+v}-y_{t}^{t+v-\frac{1}{3}}=\beta_{0}+\beta_{1}\left(y_{t-1}^{t+v-1}-y_{t-1}^{t+v-\frac{4}{3}}\right)+\varepsilon_{t}$ \\
\hline Previous release & $y_{t}^{t+v}-y_{t}^{t+v-\frac{1}{3}}=\beta_{0}+\beta_{1} y_{t}^{t+v-\frac{1}{3}}+\varepsilon_{t}$ \\
\hline Vintage-based & $y_{t}^{t+v}-y_{t}^{t+v-\frac{1}{3}}=\beta_{0}+\sum_{i=0}^{q-1} \beta_{i+1} y_{t-i}^{t+v-\frac{1}{3}}+\varepsilon_{t}$ \\
\hline \multirow[t]{2}{*}{ Threshold model } & $y_{t}^{t+v}-y_{t}^{t+v-\frac{1}{3}}=\left[\beta_{0}+\beta_{1} y_{t}^{t+v-\frac{1}{3}}\right] I\left(y_{t}^{t+v-\frac{1}{3}} \leq c\right)+\left[\beta_{2}+\beta_{3} y_{t}^{t+v-\frac{1}{3}}\right] I\left(y_{t}^{t+v-\frac{1}{3}}>c\right)+\varepsilon_{t}$ \\
\hline & Regression Models Using Multiple (n) Monthly Economic Indicators: \\
\hline New Revision & $y_{t}^{t+v}-y_{t}^{t+v-\frac{1}{3}}=\delta_{0}+\sum_{i=1}^{n} \delta_{i}\left(x_{i, t}^{t+v}-x_{i, t}^{t+v-\frac{1}{3}}\right)+\varepsilon_{t}$ \\
\hline New Observation & $y_{t}^{t+v}-y_{t}^{t+v-\frac{1}{3}}=\delta_{0}+\sum_{i=1}^{n} \delta_{i} x_{i, t+v-1 / 3}^{t+v}+\varepsilon_{t}$ \\
\hline $\begin{array}{l}\text { Updated } \\
\text { Observation }\end{array}$ & $y_{t}^{t+v}-y_{t}^{t+v-\frac{1}{3}}=\delta_{0}+\sum_{i=1}^{n} \delta_{i} x_{i, t}^{t+v}+\varepsilon_{t}$ \\
\hline Previous Release & $y_{t}^{t+v}-y_{t}^{t+v-\frac{1}{3}}=\delta_{0}+\sum_{i=1}^{n} \delta_{i} x_{i, t}^{t+v-1 / 3}+\varepsilon_{t}$ \\
\hline \multirow[t]{2}{*}{$\begin{array}{l}\text { Previous Release } \\
\text { (survey data) }\end{array}$} & $y_{t}^{t+v}-y_{t}^{t+v-\frac{1}{3}}=\delta_{0}+\sum_{i=1}^{n} \delta_{i} x_{i, t+v-2 / 3}+\varepsilon_{t}$ \\
\hline & Models With Multiple (n) Daily Financial Variables: \\
\hline MIDAS & $y_{t}^{t+v}-y_{t}^{t+v-\frac{1}{3}}=\alpha_{0}+\alpha_{1} \sum_{i=1}^{n} \sum_{j=0}^{K-1} w_{i, j}\left(\theta_{i}, K\right) x_{i, t+v-l-\left(\frac{j}{m}\right)}+\varepsilon_{t}$ \\
\hline Linear & As MIDAS, but $w_{i, j}\left(\theta_{j}, K\right)=1 / K$ for all $\mathrm{j}$ and $\mathrm{i}$. \\
\hline $\begin{array}{l}\text { STMIDAS } \\
\text { (simplified version } \\
\text { for } n=1 \text { ) }\end{array}$ & 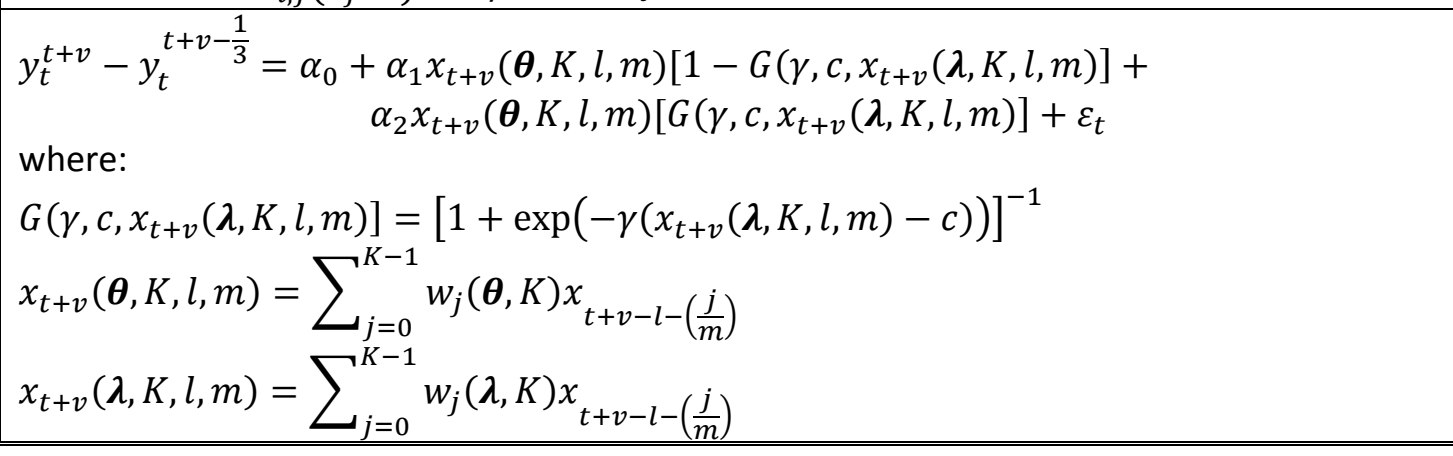 \\
\hline
\end{tabular}

Notes: The models are collected here for ease of reference. They are described in detail in the main text. 
Table 3: Using Past Vintages to Predict GDP revisions in Real Time.

\begin{tabular}{l|c|c|c|c|c|c}
\hline \hline Forecast Target: & \multicolumn{3}{|c|}{ Second Estimate: $y_{t}^{t+2 / 3}$} & \multicolumn{3}{c}{ Third Estimate: $y_{t}^{t+1}$} \\
\hline Using info up to: & \multicolumn{3}{|c|}{$y_{t}^{t+1 / 3}$} & \multicolumn{3}{c}{$y_{t}^{t+2 / 3}$} \\
\hline & All & Con. & Exp. & All & Con. & Exp. \\
\hline Mean Revision & 0.990 & 1.019 & 0.965 & 1.014 & 1.008 & 1.015 \\
AR model & 1.009 & 1.028 & 0.993 & 1.024 & 1.024 & 1.024 \\
Previous release & 0.970 & 0.980 & 0.962 & 1.016 & 1.018 & 1.015 \\
Vintage-based (q=5) & 0.986 & 0.984 & 0.988 & 1.071 & 0.991 & 1.082 \\
Vintage-based (q=14) & 0.979 & $0.936 *$ & 1.013 & 1.118 & 1.104 & 1.120 \\
Threshold model & & & & & & \\
(previous release) & 0.975 & 0.990 & 0.963 & 1.000 & 0.982 & 1.002 \\
\hline \hline
\end{tabular}

Notes: Release period 2001:M2-2013:M12. Entries are RMSFEs ratios to No-Change (random walk) forecast. 'All' indicates all observations are used to calculate RMSFEs. 'Con.' and 'Exp.' indicate that only observations in NBER designated contractionary and expansionary periods, respectively, are used.

The tests for equal forecast accuracy between the model and the no-change benchmark were computed using the Diebold and Mariano (1995) t-statistic (using heteroscedasticity-consistent standard errors).

The asterisks describe the level of significance at which the null hypothesis would be rejected $\left({ }^{* * *} 1 \%\right.$, $* * 5 \%, * 10 \%)$.

Vintages from 1966:M1 are used in model estimation. The models are re-estimated at each forecast origin with increasing windows of data during the out-of-sample period (2001-2013). 
Table 4: Monthly Economic Indicators

\begin{tabular}{|c|c|c|c|c|c|}
\hline Variable & Description & Transf. & $\begin{array}{l}\text { Vintages } \\
\text { Available }\end{array}$ & Source & $\begin{array}{l}\text { Initial } \\
\text { Release } \\
\text { delay: }\end{array}$ \\
\hline \multicolumn{6}{|c|}{ Market Moving Variables -Data Subject to Revision } \\
\hline $\begin{array}{l}\text { Ind. } \\
\text { Prod. }\end{array}$ & $\begin{array}{l}\text { Total Industrial } \\
\text { Production }\end{array}$ & $\begin{array}{l}\text { Quarterly } \\
\text { difference; } \\
\text { growth rate }\end{array}$ & $\begin{array}{l}\text { 1966:M1- } \\
\text { 2013:M12 }\end{array}$ & $\begin{array}{l}\text { RTDSM - } \\
\text { Philadelphia } \\
\text { Fed }\end{array}$ & $15-18$ days \\
\hline Empl. & $\begin{array}{l}\text { Employees on non- } \\
\text { agricultural payrolls }\end{array}$ & $\begin{array}{l}\text { Quarterly } \\
\text { difference; }\end{array}$ & $\begin{array}{l}\text { 1966:M1- } \\
\text { 2013:M12 }\end{array}$ & $\begin{array}{l}\text { RTDSM - } \\
\text { Philadelphia } \\
\text { Fed }\end{array}$ & 3-9 days \\
\hline Sales & $\begin{array}{l}\text { Retail and Food Services } \\
\text { Sales; } \\
\text { Retail Sales before } \\
\text { vintage 1992:M1. }\end{array}$ & $\begin{array}{l}\text { Quarterly } \\
\text { difference; } \\
\text { growth rate }\end{array}$ & $\begin{array}{l}\text { 1966:M1- } \\
\text { 2013:M12 }\end{array}$ & $\begin{array}{l}\text { ALFRED - St } \\
\text { Louis Fed. }\end{array}$ & $12-15$ days \\
\hline Housing & $\begin{array}{l}\text { New Privately Owned } \\
\text { Houses Started }\end{array}$ & Levels & $\begin{array}{l}\text { 1968:M2- } \\
\text { 2013:M12; }\end{array}$ & $\begin{array}{l}\text { RTDSM - } \\
\text { Philadelphia } \\
\text { Fed }\end{array}$ & $15-21$ days \\
\hline $\begin{array}{l}\text { Home } \\
\text { Sales }\end{array}$ & $\begin{array}{l}\text { New One Family Houses } \\
\text { Sold }\end{array}$ & Levels & $\begin{array}{l}\text { 1999:M7- } \\
\text { 2013:M12; }\end{array}$ & $\begin{array}{l}\text { ALFRED - St } \\
\text { Louis Fed. }\end{array}$ & 27-32 days \\
\hline $\begin{array}{l}\text { Durable } \\
\text { Orders }\end{array}$ & $\begin{array}{l}\text { Manufacturers' New } \\
\text { Orders of Durable } \\
\left.\text { Goods ( } 2^{\text {nd }} \text { release }\right)\end{array}$ & $\begin{array}{l}\text { Quarterly } \\
\text { difference; } \\
\text { growth rate }\end{array}$ & $\begin{array}{l}\text { 1999:M11- } \\
\text { 2013:M12 }\end{array}$ & $\begin{array}{l}\text { ALFRED - St } \\
\text { Louis Fed. }\end{array}$ & 30-35 days \\
\hline $\begin{array}{l}\text { Trade } \\
\text { Balance }\end{array}$ & $\begin{array}{l}\text { Trade Balance of Goods } \\
\text { and Services (from BP) } \\
\text { (BEA data for pre- } \\
\text { 1992M1) }\end{array}$ & $\begin{array}{l}\text { Quarterly Growth } \\
\text { rate of quarter's } \\
\text { accumulated } \\
\text { defict. }\end{array}$ & $\begin{array}{l}\text { 1997:M2- } \\
\text { 2013:M12 }\end{array}$ & $\begin{array}{l}\text { ALFRED - St } \\
\text { Louis Fed. }\end{array}$ & $45-53$ days \\
\hline CPI & $\begin{array}{l}\text { Consumer Price Index } \\
\text { for Urban Wage Earners } \\
\text { and Clerical Workers }\end{array}$ & $\begin{array}{l}\text { Annual } \\
\text { difference; } \\
\text { growth rate }\end{array}$ & $\begin{array}{l}\text { 1972:M7- } \\
\text { 2013:M12. }\end{array}$ & $\begin{array}{l}\text { ALFRED - St } \\
\text { Louis Fed. }\end{array}$ & $15-21$ days \\
\hline \multicolumn{6}{|c|}{ Market Moving Variable -Data not Subject to Revision } \\
\hline NAPM & $\begin{array}{l}\text { Production } \\
\text { Manufacturing Index: } \\
\text { ISM since 2002, but } \\
\text { previously NAPM. }\end{array}$ & Levels & $\begin{array}{l}\text { Obs: } \\
\text { 1959:M1- } \\
\text { 2013-M2 }\end{array}$ & $\begin{array}{l}\text { ALFRED - St } \\
\text { Louis Fed }\end{array}$ & $3-6$ days \\
\hline \multicolumn{6}{|c|}{ Merit Extra Attention Indicators - - Survey Data not Subject to Revision } \\
\hline $\begin{array}{l}\text { Cons. } \\
\text { Conf. }\end{array}$ & $\begin{array}{l}\text { University of Michigan: } \\
\text { Consumer Sentiment }\end{array}$ & $\begin{array}{l}\text { Quarterly } \\
\text { Difference of } \\
\text { quarter average. }\end{array}$ & $\begin{array}{l}\text { Obs: } \\
\text { 1978:M1- } \\
\text { 2013:M12. }\end{array}$ & $\begin{array}{l}\text { FRED- St } \\
\text { Louis Fed }\end{array}$ & $-3--1$ days \\
\hline
\end{tabular}

Notes: The NAPM time series is revised seldom and irregularly (less than once a year) to accommodate small changes in seasonal filters. Because we are mainly interested in revisions published within two months of the first announcement, we treat this variable as "not subject to revision". 
Table 5: Predicting GDP Revisions in Real Time with Economic Indicators.

Table 5A: Forecasting the Second Estimate $\left(y_{t}^{t+2 / 3}\right)$ : all the economic indicators together

\begin{tabular}{|l|c|l|l|l|l|}
\hline \multicolumn{2}{|l|}{ Information Set } & Variables Included & $\begin{array}{l}\text { All } \\
\text { Quarters }\end{array}$ & $\begin{array}{l}\text { Contraction } \\
\text { Quarters }\end{array}$ & $\begin{array}{l}\text { Expansion } \\
\text { Quarters }\end{array}$ \\
\hline New revision & $x_{t}^{t+2 / 3}-x_{t}^{t+1 / 3}$ & Ind. Prod., Empl., Sales, Housing, CPI & 0.977 & 0.986 & 0.970 \\
\hline New observations & $x_{t+1 / 3}^{t+2 / 3}$ & $\begin{array}{l}\text { Ind. Prod., Empl., Sales, Housing, CPI, } \\
\text { NAPM, Cons. Conf. }\end{array}$ & 1.008 & 1.043 & 0.979 \\
\hline $\begin{array}{l}\text { Updated } \\
\text { Observation }\end{array}$ & $x_{t}^{t+2 / 3}$ & $\begin{array}{l}\text { Ind. Prod., Empl., Sales, Housing, CPI, } \\
\text { Home Sales, Durables orders, trade } \\
\text { balance. }\end{array}$ & $0.858^{*}$ & $0.719^{*}$ & 0.956 \\
\hline Previous Release & $x_{t}^{t+1 / 3}$ & Ind. Prod., Empl., Sales, Housing, CPI & $0.928^{*}$ & 0.883 & $0.962^{*}$ \\
\hline Previous Release & $x_{t}$ & NAPM, Cons. Conf. & 0.996 & 1.014 & 0.982 \\
\hline
\end{tabular}

Table 5B: Forecasting the Third Estimate $\left(y_{t}^{t+1}\right)$ : all the economic indicators together

\begin{tabular}{|l|c|l|l|l|l|}
\hline \multicolumn{2}{|l|}{ Information Set } & Variables Included & $\begin{array}{l}\text { All } \\
\text { Quarter } \\
\mathrm{s}\end{array}$ & $\begin{array}{l}\text { Contraction } \\
\text { Quarters }\end{array}$ & $\begin{array}{l}\text { Expansion } \\
\text { Quarters }\end{array}$ \\
\hline New revision & $x_{t}^{t+1}-x_{t}^{t+2 / 3}$ & $\begin{array}{l}\text { Ind. Prod., Empl., Sales, Housing, } \\
\text { Home Sales, Durable Orders, Trade } \\
\text { Balance. }\end{array}$ & 1.010 & 0.870 & 1.029 \\
\hline New observations & $x_{t+2 / 3}^{t+1}$ & $\begin{array}{l}\text { Ind. Prod., Empl., Sales, Housing, CPI, } \\
\text { NAPM, Cons. Conf. }\end{array}$ & 1.059 & 1.081 & 1.055 \\
\hline $\begin{array}{l}\text { Updated } \\
\text { Observation }\end{array}$ & $x_{t+2 / 3}^{t+1}$ & $\begin{array}{l}\text { Ind. Prod., Empl., Sales, Housing, CPI, } \\
\text { Home Sales, Durables orders, trade } \\
\text { balance. }\end{array}$ & 1.164 & 1.105 & 1.173 \\
\hline Previous Release & $x_{t}^{t+2 / 3}$ & $\begin{array}{l}\text { Ind. Prod., Empl., Sales, Housing, CPI, } \\
\text { Home Sales, Durables Orders, Trade } \\
\text { Balance. }\end{array}$ & 1.165 & 1.093 & 1.174 \\
\hline Previous Release & $x_{t+1 / 3}$ & NAPM, Cons. Conf & 0.982 & $0.780^{* * *}$ & 1.008 \\
\hline
\end{tabular}


Table 5C: Forecasting the Second Release $\left(y_{t}^{t+2 / 3}\right)$ : one economic indicator at a time

\begin{tabular}{|c|c|c|c|c|c|c|c|c|c|c|c|c|c|c|c|}
\hline & \multicolumn{3}{|c|}{$\begin{array}{c}\text { New revision: } \\
x_{t}^{t+2 / 3}-x_{t}^{t+1 / 3}\end{array}$} & \multicolumn{3}{|c|}{$\begin{array}{c}\text { New Observation: } \\
x_{t+1 / 3}^{t+2 / 3} \\
\end{array}$} & \multicolumn{3}{|c|}{$\begin{array}{l}\text { Updated Observation: } \\
\qquad x_{t}^{t+2 / 3}\end{array}$} & \multicolumn{3}{|c|}{$\begin{array}{l}\text { Previous Release: } \\
\qquad x_{t}^{t+1 / 3}\end{array}$} & \multicolumn{3}{|c|}{$\begin{array}{l}\text { Previous Release: } \\
\qquad x_{t}\end{array}$} \\
\hline & All & Con. & Exp. & All & Con. & Exp. & All & Con. & Exp. & All & Con. & Exp. & All & Con. & Exp. \\
\hline Ind. Prod & 0.989 & 1.008 & 0.971 & 0.986 & 0.992 & 0.981 & 0.988 & 1.007 & 0.972 & 0.990 & 1.010 & 0.973 & & & \\
\hline Empl. & 0.996 & 1.024 & 0.972 & 0.985 & 1.019 & $0.956^{*}$ & 0.995 & 1.028 & 0.967 & 0.996 & 1.028 & 0.969 & & & \\
\hline Sales & 0.980 & 0.994 & 0.969 & 0.999 & 1.016 & 0.985 & $0.875^{*}$ & $0.758^{*}$ & 0.959 & $0.904 * *$ & $0.836^{*}$ & 0.955 & & & \\
\hline Housing & 0.974 & 1.006 & 0.947 & $0.964^{*}$ & 0.996 & $0.937^{* *}$ & $0.971^{*}$ & 1.005 & $0.942^{*}$ & $0.974^{*}$ & 1.008 & $0.945^{*}$ & & & \\
\hline \multirow[t]{2}{*}{$\mathrm{CPI}$} & 0.994 & 1.020 & 0.972 & 0.987 & 1.012 & 0.967 & 0.988 & 1.014 & 0.967 & 0.988 & 1.014 & 0.967 & & & \\
\hline & \multicolumn{15}{|c|}{ Indicators with publication delay $>27$ days } \\
\hline $\begin{array}{l}\text { Home Sales } \\
\text { Durable Orders } \\
\text { Trade Balance }\end{array}$ & & & & & & & $\begin{array}{l}0.98 \\
0.913 * * \\
0.990\end{array}$ & $\begin{array}{l}1.005 \\
0.877^{*} \\
1.021\end{array}$ & $\begin{array}{l}0.967 \\
0.940^{*} \\
0.965\end{array}$ & & & & & & \\
\hline & \multicolumn{15}{|c|}{ Indicators that are not subject to revision } \\
\hline NAPM & & & & $0.970^{*}$ & $0.974 * *$ & 0.967 & & & & & & & 0.984 & 1.001 & 0.970 \\
\hline Cons. Conf. & & & & 0.998 & 1.015 & 0.985 & & & & & & & 1.002 & 1.030 & 0.978 \\
\hline
\end{tabular}

Table 5D: Forecasting the Third Release $\left(y_{t}^{t+1}\right)$ : one economic indicator at a time

\begin{tabular}{|c|c|c|c|c|c|c|c|c|c|c|c|c|c|c|c|}
\hline \multirow[t]{2}{*}{ Using info up to: } & \multicolumn{3}{|c|}{$\begin{array}{l}\text { New revision: } \\
x_{t}^{t+1}-x_{t}^{t+2 / 3}\end{array}$} & \multicolumn{3}{|c|}{$\begin{array}{c}\text { New Observation: } \\
x_{t+2 / 3}^{t+1} \\
\end{array}$} & \multicolumn{3}{|c|}{$\begin{array}{c}\text { Updated Observation: } \\
x_{t}^{t+1} \\
\end{array}$} & \multicolumn{3}{|c|}{$\begin{array}{c}\text { Previous Release: } \\
x_{t}^{t+2 / 3} \\
\end{array}$} & \multicolumn{3}{|c|}{$\begin{array}{c}\text { Previous Release: } \\
x_{t+1 / 3} \\
\end{array}$} \\
\hline & All & Con. & Exp. & All & Con. & Exp. & All & Con. & Exp. & All & Con. & Exp. & All & Con. & Exp. \\
\hline Ind. Prod & 1.049 & 1.091 & 1.042 & 1.008 & 0.981 & 1.011 & 1.018 & 1.023 & 1.018 & 1.016 & 1.019 & 1.016 & & & \\
\hline Empl. & 1.022 & 1.011 & 1.023 & 1.038 & 1.135 & 1.023 & 1.018 & 1.017 & 1.019 & 1.019 & 1.014 & 1.020 & & & \\
\hline Sales & 1.017 & 0.984 & 1.022 & 1.027 & 1.094 & 1.017 & 1.009 & 0.956 & 1.016 & 1.009 & 0.964 & 1.015 & & & \\
\hline Housing & 1.014 & 1.039 & 1.071 & 1.017 & 1.018 & 1.017 & 1.040 & 1.045 & 1.040 & 1.037 & 1.040 & 1.037 & & & \\
\hline \multirow[t]{2}{*}{$\mathrm{CPI}$} & & & & 1.014 & 1.008 & 1.015 & 1.021 & 1.119 & 1.006 & 1.021 & 1.119 & 1.006 & & & \\
\hline & \multicolumn{15}{|c|}{ Indicators with publication delay $>27$ days } \\
\hline Home Sales & 1.007 & 1.041 & 1.002 & & & & 1.061 & 1.070 & 1.060 & 1.061 & 1.070 & 1.060 & & & \\
\hline Durable Orders & 1.033 & 1.054 & 1.030 & & & & 1.065 & 0.980 & 1.076 & 1.065 & 0.980 & 1.076 & & & \\
\hline \multirow[t]{2}{*}{ Trade Balance } & $0.929 *$ & $0.777^{* *}$ & 0.949 & & & & 1.051 & 1.162 & 1.035 & 1.051 & 1.162 & 1.035 & & & \\
\hline & \multicolumn{15}{|c|}{ Indicators that are not subject to revision } \\
\hline NAPM & & & & 1.016 & 1.010 & 1.017 & & & & & & & 1.014 & 1.004 & 1.016 \\
\hline Cons. Conf. & & & & 1.023 & $0.854^{* *}$ & 1.045 & & & & & & & 0.980 & $0.776 * *$ & 1.006 \\
\hline
\end{tabular}

Cons. Conf.

\begin{tabular}{l|l|l}
1.023 & $0.854 * *$ & 1.045
\end{tabular}

\begin{tabular}{l|l|l|l|l}
0.980 & $0.776 * *$ & 1.006 \\
\hline
\end{tabular}

their first release, as discussed in the main text, and see also the notes to Table 3 . The models are described in Table 2 . The CPI observed in $t$ is revised in vintage $t+2 / 3$, but not in vintage $t+1$. 
Table 6: Financial Indicators.

\begin{tabular}{|c|c|c|c|c|}
\hline Variable & Description & Transformation & "Observations & Source \\
\hline SP500 & $\begin{array}{l}\text { Standard \& Poor's } 500 \\
\text { Leading Companies }\end{array}$ & $\begin{array}{l}\text { Daily Percentage } \\
\text { Returns }\end{array}$ & $\begin{array}{l}\text { 1959-M1-02: } \\
\text { 2013-M12-30. }\end{array}$ & \multirow[t]{5}{*}{$\begin{array}{l}\text { FRED- St } \\
\text { Louis Fed }\end{array}$} \\
\hline DJIA & $\begin{array}{l}\text { Dow Jones Industrial } \\
\text { Average }\end{array}$ & $\begin{array}{l}\text { Daily Percentage } \\
\text { Returns }\end{array}$ & $\begin{array}{l}\text { 1959-M1-02: } \\
\text { 2013-M12-30. }\end{array}$ & \\
\hline Spread & $\begin{array}{l}\text { 10-year Treasury } \\
\text { Constant Maturity Rate - } \\
\text { 3-month Treasury Bill } \\
\text { (Seconday Market) }\end{array}$ & $\begin{array}{l}10 \text {-year rate }-3 \text { - } \\
\text { month rate. }\end{array}$ & $\begin{array}{l}\text { 1962-M1-02- } \\
\text { 2013-M12-30. }\end{array}$ & \\
\hline Short-rate & $\begin{array}{l}\text { 3-month Treasury Bill } \\
\text { (Seconday Market) }\end{array}$ & Levels (rate) & $\begin{array}{l}\text { 1962-M1-02- } \\
\text { 2013-M12-30. }\end{array}$ & \\
\hline Baa spread & $\begin{array}{l}\text { Moody's BAA yield - } 10 \\
\text { year Treasury }\end{array}$ & Levels (rate) & $\begin{array}{l}\text { 1986-M1-02- } \\
\text { 2013-M12-30 }\end{array}$ & \\
\hline
\end{tabular}


Table 7: Predicting GDP Revisions in Real Time with Daily Financial Indicators.

Table 7A: Forecasting the Second Estimate $\left(y_{t}^{t+2 / 3}\right)$ : all financial indicators together

\begin{tabular}{l|l|c|c|c|c|c|c|c|c|c}
\hline \hline \multicolumn{1}{l|}{ Information up to: } & \multicolumn{3}{c|}{$x_{t}(\mathrm{~K}=60)$} & \multicolumn{3}{c|}{$x_{t+1 / 3}(\mathrm{~K}=20)$} & \multicolumn{3}{c}{$x_{t+d b}(\mathrm{~K}=60)$} \\
\hline Variables & Models & All & Con. & Exp. & All & Con. & Exp. & All & Con. & Exp. \\
\hline SP500, DJIA & MIDAS & 0.986 & 0.965 & 1.001 & 0.998 & 1.052 & $0.951^{*}$ & 1.044 & 1.129 & 0.969 \\
& Linear & 0.993 & 1.030 & 0.962 & 0.997 & 1.022 & 0.976 & 1.021 & 1.122 & $0.931^{*}$ \\
\hline Spread, Short-rate & MIDAS & 1.004 & 1.036 & 0.977 & 1.004 & 1.035 & 0.978 & 1.004 & 1.039 & 0.975 \\
& Linear & 1.005 & 1.045 & 0.971 & 1.002 & 1.034 & 0.976 & 1.003 & 1.044 & 0.969 \\
\hline SP500, DJIA, Baa Sp, & MIDAS & 1.025 & 0.957 & 1.077 & 0.981 & 0.967 & 0.992 & 1.042 & 1.123 & 0.971 \\
Short-rate, Spread & Linear & 1.066 & 1.121 & 1.019 & 1.025 & 1.017 & 1.032 & 1.049 & 1.094 & 1.011 \\
\hline \hline
\end{tabular}

Table 7B: Forecasting the Third Estimate $\left(y_{t}^{t+1}\right)$ : all financial indicators together

\begin{tabular}{l|l|c|c|c|c|c|c|c|c|c}
\hline \hline Information up to: & \multicolumn{3}{c|}{$x_{t}(\mathrm{~K}=60)$} & \multicolumn{3}{c|}{$x_{t+1 / 3}(\mathrm{~K}=20)$} & \multicolumn{3}{c}{$x_{t+d b}(\mathrm{~K}=60)$} \\
\hline Variables & Models & All & Con. & Exp. & All & Con. & Exp. & All & Con. & Exp. \\
\hline SP500, DJIA & MIDAS & 1.041 & 1.203 & 1.016 & $0.920^{*}$ & 0.824 & $0.933^{*}$ & 1.075 & 1.284 & 1.042 \\
& Linear & 1.029 & 1.166 & 1.008 & 1.028 & 0.982 & 1.034 & 1.026 & 0.998 & 1.030 \\
\hline Spread, Short-rate & MIDAS & 1.049 & 1.107 & 1.040 & 1.042 & 1.073 & 1.037 & 1.065 & 1.108 & 1.058 \\
& Linear & 1.033 & 1.072 & 1.027 & 1.043 & 1.088 & 1.036 & 1.060 & 1.092 & 1.055 \\
\hline SP500, DJIA, BAA SP, & MIDAS & 1.066 & 1.212 & 1.044 & 0.986 & 1.052 & 0.984 & 1.078 & 1.192 & 1.068 \\
Short-rate, Spread & Linear & 1.051 & 1.114 & 1.041 & 1.112 & 1.158 & 1.035 & 1.059 & 1.187 & 1.039 \\
\hline \hline
\end{tabular}


Table 7C: Forecasting the Second Release $\left(y_{t}^{t+2 / 3}\right)$ : one financial indicator at a time

\begin{tabular}{|c|c|c|c|c|c|c|c|c|c|c|}
\hline \multicolumn{2}{|c|}{ Information up to: } & \multicolumn{3}{|c|}{$x_{t}(\mathrm{~K}=60)$} & \multicolumn{3}{|c|}{$x_{t+1 / 3}(\mathrm{~K}=20)$} & \multicolumn{3}{|c|}{$x_{t+d b}(\mathrm{~K}=60)$} \\
\hline Variables & Models & All & Con. & Exp. & All & Con. & Exp. & All & Con. & Exp. \\
\hline \multirow[t]{3}{*}{ SP500 } & MIDAS & 0.972 & $0.944 *$ & 0.994 & 0.989 & 1.027 & $0.958 *$ & 1.024 & 1.083 & 0.974 \\
\hline & Linear & 1.001 & 1.032 & 0.976 & 0.993 & 1.016 & 0.973 & 1.008 & 1.062 & 0.963 \\
\hline & STMIDAS & 1.027 & 1.037 & 1.019 & $0.955^{*}$ & $0.958^{* *}$ & 0.952 & 1.057 & 0.990 & 1.109 \\
\hline \multirow[t]{3}{*}{ DJIA } & MIDAS & 0.974 & 0.962 & 0.983 & 0.986 & 1.015 & 0.961 & 1.043 & 1.118 & 0.979 \\
\hline & Linear & 1.002 & 1.035 & 0.973 & 0.994 & 1.023 & 0.970 & 1.023 & 1.097 & 0.959 \\
\hline & STMIDAS & 0.992 & 1.001 & 0.984 & 0.970 & $0.957 *$ & 0.980 & 1.021 & 1.021 & 1.022 \\
\hline \multirow[t]{3}{*}{ Spread } & MIDAS & 0.999 & 1.024 & 0.978 & 0.999 & 1.029 & 0.974 & 0.994 & 1.030 & 0.964 \\
\hline & Linear & 0.999 & 1.035 & 0.969 & 0.998 & 1.028 & 0.974 & 0.997 & 1.032 & 0.967 \\
\hline & STMIDAS & 0.967 & 0.981 & 0.955 & 0.994 & 1.003 & 0.986 & 0.998 & 1.032 & 0.970 \\
\hline \multirow[t]{3}{*}{ Short-rate } & MIDAS & 1.001 & 1.039 & 0.969 & 1.002 & 1.050 & 0.962 & 1.005 & 1.056 & 0.962 \\
\hline & Linear & 0.998 & 1.035 & 0.967 & 1.000 & 1.044 & 0.962 & 1.003 & 1.051 & 0.963 \\
\hline & STMIDAS & 1.129 & 1.170 & 1.094 & 1.044 & 1.142 & 0.958 & 1.100 & 1.201 & 1.012 \\
\hline \multirow[t]{3}{*}{ Baa spread } & MIDAS & 0.967 & 1.077 & 0.967 & 1.007 & 1.100 & 0.978 & 1.058 & 1.156 & 0.972 \\
\hline & Linear & 0.984 & 1.059 & 0.970 & 1.003 & 1.092 & 0.974 & 1.030 & 1.098 & 0.972 \\
\hline & STMIDAS & 0.964 & 0.976 & 0.954 & 1.054 & 1.168 & 1.050 & 1.389 & 1.727 & 1.037 \\
\hline
\end{tabular}

Table 7D: Forecasting the Third Release $\left(y_{t}^{t+1}\right)$ : one financial indicator at a time

\begin{tabular}{l|l|c|c|c|c|c|c|c|c|c}
\hline \multicolumn{3}{l|}{ Information up to: } & \multicolumn{3}{|c|}{$x_{t}(\mathrm{~K}=60)$} & \multicolumn{3}{c|}{$x_{t+1 / 3}(\mathrm{~K}=20)$} & \multicolumn{3}{c}{$x_{t+d b}(\mathrm{~K}=60)$} \\
\hline Variables & Models & All & Con. & Exp. & \multicolumn{1}{c}{ All } & Con. & Exp. & All & Con. & Exp. \\
\hline SP500 & MIDAS & 1.019 & 0.985 & 1.023 & $0.929^{* *}$ & 0.870 & $0.937^{*}$ & 1.064 & 1.380 & 1.011 \\
& Linear & 1.029 & 1.092 & 1.020 & 1.018 & 0.993 & 1.021 & 1.025 & 1.039 & 1.023 \\
& STMIDAS & 1.135 & 1.275 & 1.113 & $0.928^{*}$ & 0.919 & $0.929^{*}$ & 1.076 & 1.068 & 1.077 \\
\hline DJIA & MIDAS & 1.035 & 1.171 & 1.014 & $0.918^{* *}$ & $0.772^{*}$ & $0.937^{*}$ & 1.028 & 1.127 & 1.013 \\
& Linear & 1.034 & 1.147 & 1.016 & 1.016 & 1.006 & 1.017 & 1.012 & 1.050 & 1.007 \\
& STMIDAS & 1.132 & 1.556 & 1.058 & $0.931^{* *}$ & $0.804^{* *}$ & $0.948^{*}$ & 1.026 & 1.071 & 1.019 \\
\hline \multirow{3}{*}{ Spread } & MIDAS & 1.025 & 1.022 & 1.025 & 1.029 & 1.028 & 1.029 & 1.021 & 1.015 & 1.021 \\
& Linear & 1.018 & 1.012 & 1.019 & 1.018 & 1.013 & 1.019 & 1.017 & 1.010 & 1.019 \\
& STMIDAS & 1.103 & 1.188 & 1.091 & 1.055 & 1.091 & 1.050 & 1.087 & 1.160 & 1.077 \\
\hline \multirow{5}{*}{ Bart-rate spread } & MIDAS & 1.046 & 1.109 & 1.037 & 1.051 & 1.121 & 1.041 & 1.065 & 1.142 & 1.053 \\
& Linear & 1.036 & 1.088 & 1.029 & 1.047 & 1.112 & 1.038 & 1.055 & 1.123 & 1.045 \\
& STMIDAS & 1.072 & 1.348 & 1.026 & 1.072 & 1.349 & 1.027 & 1.071 & 1.347 & 1.026 \\
\hline \hline & MIDAS & 1.028 & 1.079 & 1.021 & 1.028 & 1.094 & 1.018 & 1.059 & 1.079 & 1.022 \\
& Linear & 1.020 & 1.064 & 1.014 & 1.027 & 1.090 & 1.018 & 1.044 & 1.068 & 1.015 \\
& STMIDAS & 1.145 & 1.425 & 1.099 & 1.061 & 1.191 & 1.041 & 1.342 & 1.409 & 1.118 \\
\hline
\end{tabular}

Notes to Table 7. The forecast evaluation period includes releases from 2001:M2 to 2013:M12.

The table records RMSFEs relative to that of the benchmark RMSFE.

The forecasting models are described in Table 2. $x_{t+d b}$ refers to the value of the indicator on the business day immediately before the release date (release dates only from 1975).

Qualitative results do not change if we compute the spread using the 5-year rate instead of the 10-year rate. 
Table 8: Evaluating the Incremental Predictive Power of Daily Stock Returns ( $x_{t+1 / 3}$ ) for Predicting Data Revisions in Real Time.

\begin{tabular}{|c|c|c|c|c|c|c|c|}
\hline \multirow{2}{*}{$\begin{array}{l}\text { Forecast Target: } \\
\text { Variables Included: }\end{array}$} & \multicolumn{3}{|c|}{ Second Estimate: $y_{t}^{t+2 / 3}$} & \multirow{2}{*}{\begin{tabular}{|l} 
Forecast Target: \\
Variables Included:
\end{tabular}} & \multicolumn{3}{|c|}{ Third Estimate: $y_{t}^{t+1}$} \\
\hline & All & Con. & Exp. & & All & Con. & Exp. \\
\hline $\begin{array}{l}\text { Updated Observations } \\
\text { (Ind. Prod., Empl., Sales, Housing, } \\
\text { CPI, Home Sales, Durables orders, } \\
\text { Trade Balance) }\end{array}$ & 0.576 & 0.774 & 0.525 & $\begin{array}{l}\text { Previous Release } \\
\text { (NAPM, Cons. Conf) }\end{array}$ & 0.274 & 0.185 & 0.289 \\
\hline+ SP500 & 0.991 & $0.970^{*}$ & 1.001 & + SP500 & $0.932 *$ & 0.993 & $0.926^{*}$ \\
\hline + DJIA & 0.997 & 0.986 & 1.002 & + DJIA & $0.934 *$ & 0.886 & $0.938^{*}$ \\
\hline
\end{tabular}

Notes: Forecast evaluation period 2001:M2-2013:M12.

The first row (italicized) records the RMSFE for the best regression model with economic indicators.

The remaining rows are RMSFE ratios to the first row values when daily financial variables are add to the best economic indicator specification using a MIDAS model. 
Table 9: The Impact of Announcement Surprises on Equity Returns.

\begin{tabular}{l|c|c|c|c|c|c}
\hline & \multicolumn{3}{|c|}{ Second Release } & \multicolumn{3}{c}{ Third Release } \\
\hline & All & Con. & Exp. & All & Con. & Exp. \\
\hline Consensus & 0.038 & $0.632^{* *}$ & -0.134 & 0.036 & 0.270 & -0.025 \\
& $(0.125)$ & $(0.238)$ & $(0.111)$ & $(0.086)$ & $(0.293)$ & $(0.095)$ \\
\hline $\mathrm{R}^{2}$ & 0.003 & 0.298 & 0.024 & 0.001 & 0.025 & 0.001 \\
\hline \hline MIDAS & 0.081 & $0.940 * *$ & $-0.159 *$ & 0.114 & 0.267 & 0.091 \\
& $(0.111)$ & $(0.174)$ & $(0.093)$ & $(0.082)$ & $(0.405)$ & $(0.073)$ \\
\hline $\mathrm{R}^{2}$ & 0.007 & 0.653 & 0.030 & 0.012 & 0.026 & 0.011 \\
\hline \hline
\end{tabular}

Note: The dependent variable is the daily return on the day of the announcement. Estimates obtained from pooled OLS, with White standard errors reported in brackets. Number of cross sections: 2 (SP500 and DJIA). Number of observations for each cross-section: 52 (the number of quarterly data releases 2001-2013). The MIDAS forecasts use daily data up to the month of the advance estimate, and include economic variables, as in Table 8.

Table 10: The Impact of Announcement Surprises, Expected and Surprise Revisions on Equity Returns.

\begin{tabular}{l|c|c|c|c|c|c}
\hline \hline & \multicolumn{3}{|c|}{ Second Release } & \multicolumn{3}{c}{ Third Release } \\
\hline & All & Con. & Exp. & All & Con. & Exp. \\
\hline AS (Consensus) & 0.053 & $0.783^{* *}$ & -0.146 & 0.083 & 0.103 & 0.051 \\
& $(0.137)$ & $(0.281)$ & $(0.129)$ & $(0.106)$ & $(0.336)$ & $(0.110)$ \\
Future & 0.067 & $-0.403^{*}$ & 0.143 & 0.121 & $1.041^{* *}$ & -0.136 \\
Revision & $(0.113)$ & $(0.235)$ & $(0.126)$ & $(0.171)$ & $(0.365)$ & $(0.141)$ \\
\hline $\mathrm{R}^{2}$ & 0.008 & 0.400 & 0.038 & 0.019 & 0.381 & 0.022 \\
\hline \hline AS (MIDAS) & 0.124 & $0.937^{* * *}$ & -0.159 & $0.186^{*}$ & 0.479 & $0.221^{* *}$ \\
& $(0.127)$ & $(0.184)$ & $(0.114)$ & $(0.109)$ & $(0.318)$ & $(0.099)$ \\
Future & 0.097 & -0.008 & 0.099 & 0.107 & $1.146^{* * *}$ & -0.177 \\
Revision & $(0.120)$ & $(0.120)$ & $(0.133)$ & $(0.182)$ & $(0.340)$ & $(0.149)$ \\
\hline $\mathrm{R}^{2}$ & 0.020 & 0.653 & 0.041 & 0.041 & 0.453 & 0.073 \\
\hline \hline AS (MIDAS) & 0.121 & $0.968^{* * *}$ & -0.160 & $0.179 *$ & 0.036 & $0.210^{* *}$ \\
& $(0.130)$ & $(0.186)$ & $(0.115)$ & $(0.102)$ & $(0.385)$ & $(0.099)$ \\
Expected & 0.057 & -0.126 & 0.020 & 0.086 & $1.019 * * *$ & -0.191 \\
Revision & $(0.123)$ & $(0.206)$ & $(0.168)$ & $(0.135)$ & $(0.224)$ & $(0.137)$ \\
Surprise & 0.096 & 0.003 & 0.099 & 0.107 & $1.134^{* * *}$ & -0.151 \\
Revision & $(0.129)$ & $(0.125)$ & $(0.143)$ & $(0.192)$ & $(0.353)$ & $(0.150)$ \\
\hline $\mathrm{R}^{2}$ & 0.021 & 0.664 & 0.041 & 0.043 & 0.543 & 0.098 \\
\hline \hline
\end{tabular}

Note: See notes to Table 9. AS(Consensus) is the announcement surprise, calculated using the consensus forecasts. AS(MIDAS) is the announcement surprise, calculated using MIDAS forecasts (using daily data up to the month of the first-release, and economic variables as in Table 8). The calculation of Expected Revision and Surprise Revision is fully explained in the main text, section 4. Sample period: 2001M12011M12 (total of 44 observations for each cross-section). 